\title{
Solvent Effect on Dipeptide Bond Formation: Glycine as a Case Study
}

\author{
Sofiene Achour, Zied Hosni, Sarra Darghouth, Christopher Syme
}

Submitted date: 17/08/2019 Posted date: 19/08/2019

Licence: CC BY-NC-ND 4.0

Citation information: Achour, Sofiene; Hosni, Zied; Darghouth, Sarra; Syme, Christopher (2019): Solvent Effect on Dipeptide Bond Formation: Glycine as a Case Study. ChemRxiv. Preprint.

Peptide bond formation is a crucial chemical process that dominates most biological mechanisms and is claimed to be a governing factor in the origin of life. Dipeptides made from glycine are studied computationally via Density Functional Theory (DFT) using two different basis sets. This reaction was investigated from both a thermodynamic and kinetic point of view. The effect of explicit solvation via the introduction of discreet solvent molecules was investigated. Water, methanol, and cyclohexane were all employed as solvent media in addition to gas to investigate their effects on the mechanism of peptide bond formation. This computational investigation revealed that methanol is slightly better than water to leverage peptide bond formation both kinetically and thermodynamically, while cyclohexane, a non-polar and non-protic solvent, is the least effective after gas as a medium of solvation. Energetic results in the gas environment are very close to those obtained in polar and protic solvents, suggesting that peptide bonds can be formed under interstellar conditions.

File list (4)

Solvents effect on dipeptide bond formation glycine as a ... (251.26 KiB) view on ChemRxiv • download file Solvents effect on dipeptide bond formation glycine as a ... (825.67 KiB) view on ChemRxiv • download file Figures.docx (1.30 MiB) view on ChemRxiv • download file 


\title{
Solvent effect on dipeptide bond formation: glycine as a case study
}

\author{
Sofiene Achour, ${ }^{1}$ Zied Hosni, ${ }^{2}$ and Sarra Darghouthi, ${ }^{3}$ Christopher Syme ${ }^{4}$ \\ Correspondence to: Zied Hosni (zied.hosni@strath.ac.uk)
}

\begin{abstract}
Peptide bond formation is a crucial chemical process that dominates most biological mechanisms and is claimed to be a governing factor in the origin of life. Dipeptides made from glycine are studied computationally via Density Functional Theory (DFT) using two different basis sets. This reaction was investigated from both a thermodynamic and kinetic point of view. The effect of explicit solvation via the introduction of discreet solvent molecules was investigated. Water, methanol, and cyclohexane were all employed as solvent media in addition to gas to investigate their effects on the mechanism of peptide bond formation. This computational investigation revealed that methanol is slightly better than water to leverage peptide bond formation both kinetically and thermodynamically, while cyclohexane, a non-polar and non-protic solvent, is the least effective after gas as a medium of solvation. Energetic results in the gas environment are very close to those obtained in polar and protic solvents, suggesting that peptide bonds can be formed under interstellar conditions.
\end{abstract}

\section{Introduction}

Peptide bond formation is a vital process that has attracted the attention of the scientific community as it is a key concept in understanding the origin of life. This exceptional type of chemical bond is required in any biological mechanism that involves amino acid interactions and the formation of biomolecules under prebiotic conditions. ${ }^{[1,2]}$ Since the beginning of the $20^{\text {th }}$ century, polypeptides of various types and structures have been synthesised. Although several attempts were carried out in the aim of forming peptide bonds with high yield, these reactions usually require activated amino-acid precursors and heterogeneous supports. ${ }^{[3]}$ The synthesis of peptides has also been performed in the gas phase such as in the case of ion-molecule reactions containing methionine and glutamic acid. ${ }^{[4]}$ The peptide bond formation in this particular medium is extremely relevant in astro-chemistry because it enables the study of prebiotic molecular synthesis in the interstellar medium. ${ }^{[5]}$ A radiochemical search revealed the presence of the simplest amino acid, glycine, and many amino acids have been isolated in different meteorites. ${ }^{[6]}$ Although simple entities such as $\mathrm{H} 2, \mathrm{CO}, \mathrm{HCN}$ were more abundant, biological building blocks such as the simplest amino acids were spotted in interstellar ice together with methanol, ammonia and hydrogen cyanide. ${ }^{[7]}$

Several studies have demonstrated that peptides can self-replicate under certain conditions. ${ }^{[8-17]}$ The simplest example of peptide bond formation involves two glycine molecules via the following condensation reaction:

$$
\text { 2Gly -> Gly-Gly + H2O }
$$

Glycine has the peculiarity of lacking a chiral centre and is therefore optically inactive. Its neutral form is generally favoured in the gas phase, while its zwitterionic form is favoured in solution and in the solid state, ${ }^{[18]} \mathrm{Li}$ and coworkers studied the solvent effects on the cyclisation of dipeptide from neutral monomers. ${ }^{[19]}$ Numerous computational studies have been conducted to investigate the formation mechanism of glycine through a radical-radical reaction involving t-HOCO and $\mathrm{CH}_{2} \mathrm{NH}_{2}{ }^{[20]}$ Jensen et al. were interested in the uncatalysed stepwise and concerted routes of peptide bond formation. The authors explained the effect of the entropy and the electronic structures of the transition state (TS) on the energetic barrier heights controlling this reaction. ${ }^{[21]}$ 
Noncovalent interactions in diglycine and diglycine-water models were investigated computationally by Liu and coworkers. They indicated that the first water molecule binds simultaneously to both oxygen atoms of the carboxylate forming two loose $\mathrm{H}$-bonds. ${ }^{[22]}$ It was revealed by Bhunia et al., that the kinetic preference and the concerted/stepwise mechanism is very sensitive to the level of theory that has been used. For instance, B3LYP/6-31G(d,p) favoured the concerted route to form the peptide bond. Whereas, it was the stepwise route that was dominant when the M062X/6-31G(d,p) level of theory was used. ${ }^{[23]}$

Van Dornshuld et al. highlighted the stabilising effect of a water molecule on the cis and trans products

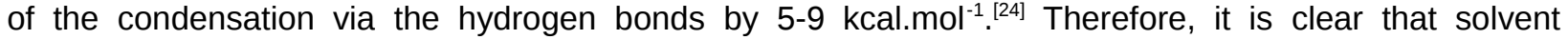
interactions have a drastic effect on the condensation process. This has been investigated computationally by implicitly surrounding the glycine within a cavity of continuum defined by macroscopic properties such as the dielectric constant. This approach represents properly nonspecific and long-range interactions. A second approach is available and consists of adding one or more discrete solvent molecules. This method targets, generally, to spot the catalytic actions and the specific effects of the solvent. ${ }^{[25]}$ The number of explicit solvent molecules required to stabilize glycine is still not clear. For example, Jensen and Gordon used MP2 calculations on structures optimized at the HF level of theory and included diffuse and polarization functions for the basis set. They claimed that at least two water molecules are required to stabilize the glycine zwitterion. ${ }^{[26]}$ Whereas, Ding and Krogh-Jespersen found that one molecule of water is sufficient to stabilize glycine at the same level of theory and by exploiting a 6-31G basis set with polarization and diffuse functions in some atoms. ${ }^{[27]}$ Tortonda and coworkers studied the stabilization of neutral glycine with an explicit water molecule with MP2 calculation and found that the zwitterionic form cannot be stabilized by a single water entity. The same authors concluded that for this type of system, the discrete and continuum solvent models are complementary to explain water-glycine interactions and found that several explicit water molecules did not affect the mechanism of the concerted zwitterion formation. ${ }^{[25]}$ Zou et al. investigated the microsolvation of the glycine in the presence of different number of explicit methanol molecule via DFT calculations. They found that the zwitterionic form can be stabilized by one methanol entity. If two or three methanol molecules are involved, they tend to be located near the carboxylic acid group of the neutral form of glycine. A bridge of methanol forms between the acid and the amino group in the zwitterionic case. When five or six methanols are employed, the zwitterionic and the neutral form of glycine tend to be isoenergetic. The authors concluded that up to nine methanols are required to fully solvate a glycine molecule. ${ }^{[28]}$ Ab initio, MP2 and B3LYP were all exploited with different basis sets to study the interaction between glycine and hydrogen peroxide. The authors stated that the stability of the solvent-glycine complex is sensitive to the selected glycine conformation. ${ }^{[29]}$

In this paper, we investigate the thermodynamic and kinetic mechanism of peptide bond formation for glycine in polar and non-polar solvents that are defined both implicitly and explicitly. The molecules of water, methanol and cyclohexane studied here play the role of solvents and also the catalyst for the dipeptide formation when their concentration is low and the probability of collision with the amino acid is less frequent. The results of these mechanisms are compared with those obtained in vacuum.

\section{Computational method}

Density functional theory (DFT) was employed at B3LYP level of theory and with the simple 6-31G(d,p) and the extended $6-311++(2 d, 2 p)$ (i.e. with double polarization and diffuse basis sets) for a better explanation of non-covalent bonds and solvent effects. The B3LYP functional is a combination of Becke's three parameters functional and nonlocal correlation provided by Lee, Yang and Parr (LYP). ${ }^{[30,31]}$ This method is relevant to simulate organic reactions and transition states. The same level of theory was kept to perform harmonic vibrational calculations with the two basis sets for each case in order to confirm the presence of one imaginary frequency in the case of a transition state and the absence of imaginary frequencies for the optimized structures at their energetic minima. The Berny algorithm was employed to optimize the structure of interest to a transition state. Intrinsic reaction coordinate calculations followed each optimization of the reactant, product and transition state to check the connection of the latter to the right minima. ${ }^{[32]}$ The Gibbs free energy was employed to evaluate the kinetic factor instead of the electronic energy difference from the IRC plots. All calculations were carried out using the Gaussian 09 package. ${ }^{[33]}$ 
Only the concerted pathway leading to the trans isomer was considered in this study because it was

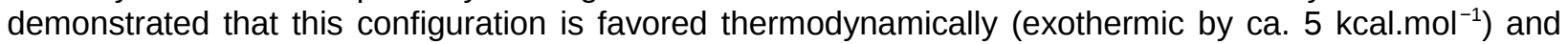
kinetically (barrier height $\approx 32 \mathrm{kcal} . \mathrm{mol}^{-1}$ and ca. $8 \mathrm{kcal} \cdot \mathrm{mol}^{-1}$ than the concerted cis pathway) according to the $\operatorname{CCSD}(\mathrm{T})$-F12/haTZ electronic energies. ${ }^{[24]}$ The stepwise pathways have slightly larger barrier heights (by 4-8 kcal.mol ${ }^{-1}$ ). Solvent effects were included explicitly by adding a molecule of solvent to the reaction between the two glycines or implicitly by exploiting the Polarizable Continuum Model (PCM) that is based on the calculation of the molecular free energy in solution as the sum over three terms:

$$
G_{s o l}=G_{e s}+G_{d r}+G_{c a v}
$$

These components represent the electrostatic (es) and the dispersion-repulsion (dr) contributions to the free energy, and the cavitation energy (cav) through interlocking van der Waals spheres centred at atomic positions. ${ }^{[34]}$

\section{Results}

\section{Non-explicitly assisted dipeptide formation}

The comparison between the reaction enthalpy in gas and in Polarized Continuum Model reveals that the formation of the peptide bond is exothermic in all the cases. The reaction was more exothermic in polar solvents such as in water and methanol. This can be quantitatively correlated to the dielectric constant, the dipole moment and the van der Waals volume of the solvents of interest. For instance, water and methanol have a dipole moment equal to $1.85 \mathrm{D}$ and $1.7 \mathrm{D}$, respectively. Conversely, the dipole moment of cyclohexane is nil. The reaction in the implicit solvent and in gas was spontaneous, too. Indeed, $\Delta \mathrm{G}_{0}$ equaled approximately $-9 \mathrm{kcal}^{\mathrm{mol}}{ }^{-1}$ in both cases. Kinetically, Table 1 shows that the energetic barrier was $46.11 \mathrm{kcal} . \mathrm{mol}^{-1}$ in gas with the extended basis set and $44.38 \mathrm{kcal}^{\mathrm{mol}}{ }^{-1}$ in water, which leads to the conclusion that these types of media had no significant effect on the rate of the reaction. The utilization of the simple $(6-31 G)$ or the extended $(6-311++(2 d, 2 p))$ basis set gave similar results for all the thermodynamic descriptors. Indeed, the energetic difference did not exceed $2 \mathrm{kcal}^{\mathrm{mol}} \mathrm{m}^{-1}$.

The IRC approach to determine the path of the chemical reaction between two glycines suggested the formation of a 4 membered atomic ring in the transition state as illustrated in Figure 1. The suggested mechanism is illustrated in Figure 2. It starts with the positioning of the carboxylic functional group in proximity to its amine homologue. In a concerted way, a bridge is formed between the two molecules through the carbon atoms of the carboxylic acid and the nitrogen of the amine group. Simultaneously, the hydroxyl group linked to the carbon is liberated in the form of water after withdrawing the mobile hydrogen atom that was connected to the nitrogen of the amine function.

\begin{tabular}{|c|c|c|c|c|}
\hline Basis sets & $\Delta \mathrm{H}_{\mathrm{o}}$ & $\Delta \mathrm{G}_{0}$ & $E_{a}$ & $\Delta \mathrm{G}^{\#}$ \\
\hline $6-31 G$ & -7.8 & -8 & 27.76 & 44.95 \\
\hline $6-311++(2 d, 2 p)$ & -7.48 & -7.86 & 27.70 & 46.11 \\
\hline
\end{tabular}

The comparison of the structures of reagents, products and transition states revealed that the distance between the closest nitrogen of the first glycine and the carbon of the neighbouring molecule decreased from D1 $=3.391 \AA$ to $\mathrm{D} 5=1.604 \AA$ during the TS. This distance was stabilized to $\mathrm{D} 9=1.353 \AA$ when the product was formed. By the same scenario, the dihedral angle between the $\mathrm{C}-\mathrm{N}$ bond of the first glycine and the $\mathrm{C}-\mathrm{C}$ bond of the second glycine increased progressively from DA1 $=114.83^{\circ}$ at the starting point to DA2 $=137.28^{\circ}$ in the TS structure and finally to DA3 $=177.82^{\circ}$ in the product. It is noteworthy that during the transition state, the distance between the nitrogen approaching from the other glycine started to lose the link with its hydrogen. Therefore, the distance of the $\mathrm{N}-\mathrm{H}$ was D4 $=1.011 \AA$ in the reagent then increased to $\mathrm{D} 8=1.156 \AA$. 


\begin{tabular}{|c|c|c|c|c|c|}
\hline \multicolumn{6}{|c|}{ methanol $(\mathrm{MeOH})$, and cyclohexane $\left(\mathrm{C}_{6} \mathrm{H}_{6}\right)$ in kcal.mol ${ }^{-1}$. } \\
\hline $\begin{array}{c}\text { Non } \\
\text { assisted } \\
\text { media }\end{array}$ & $\begin{array}{c}\text { Basis } \\
\text { sets }\end{array}$ & $\Delta \mathrm{H}_{0}$ & $\Delta \mathrm{G}_{0}$ & $\mathrm{E}_{\mathrm{a}}$ & $\Delta \mathrm{G}^{\#}$ \\
\hline in PCM & $A$ & -10.65 & -9.1 & 28 & 42.46 \\
\hline (water) & $\mathrm{B}$ & -10.04 & -7.6 & 29.40 & 44.38 \\
\hline in PCM & A & -10.62 & -9.2 & 27.61 & 42.5 \\
\hline$(\mathrm{MeOH})$ & $\mathrm{B}$ & -10.02 & -8.79 & 29.00 & 43.34 \\
\hline in PCM & $A$ & -9.18 & -8.8 & 26.40 & 44.29 \\
\hline$\left(\mathrm{C}_{6} \mathrm{H}_{6}\right)$ & B & -7.87 & -7.46 & 26.55 & 46.4 \\
\hline \multicolumn{6}{|c|}{$6-31 G,(B) 6-311++(2 d, 2 p)$} \\
\hline
\end{tabular}

Similarly, in the other glycine, the C-O moiety involved in peptide bond formation was dissociated progressively from its corresponding molecule and migrates to form a water molecule with the hydrogen dissociated from the nitrogen of the neighbouring molecule in the case of the gas phase. Thus, D2 increased from $1.357 \AA$ in the reagent to D6 $=1.913 \AA$ in the transition state. The glycine reaction was also investigated with PCM solvation model, which revealed that the activation energy obtained in gas phase is very close the ones obtained with the implicit solvation and depicted in Table 2.

\section{Explicitly solvent-assisted dipeptide formation}

\section{Water assistance}

When a water molecule was introduced explicitly to leverage the formation of the peptide bond, one could follow the migration of atoms between the two glycine molecules and the electronic exchange through the water molecule. The five distances that were used to monitor this mechanism are summarized in the table that joins Figure 4. D2 to D6 and D8 to D12 showed the distances between the six atoms that were involved in the reaction at the starting point and at the TS, respectively. The peptide bond was slightly longer at the TS with water assistance comparing to gas medium reaction.

Peptide bond formation is exothermic in water with a $\Delta \mathrm{H}_{0}$ equal to $-12.83 \mathrm{kcal}_{\text {. } \mathrm{mol}^{-1}}$ with the extended basis set and the water molecule expressed explicitly with the glycines. This reaction is spontaneous for the peptide under the same conditions. Therefore, $\Delta \mathrm{G}_{0}$ is equal to $-8.01 \mathrm{kcal} . \mathrm{mol}^{-1}$ and $-7.6 \mathrm{kcal}^{\mathrm{mol}}{ }^{-1}$, respectively, in explicit and implicit water solvent at the extended basis set. When the water molecule was defined explicitly, the energetic barrier depicted in Table 3 was $3.1 \mathrm{kcal}^{\mathrm{mol}}{ }^{-1}$ lower than its homologue in $\mathrm{PCM}\left(\Delta \mathrm{G}^{\#}\right.$ equals $41.28 \mathrm{kcal} . \mathrm{mol}^{-1}$ in the explicitly assisted reaction).

\begin{tabular}{|c|c|c|c|c|}
\hline Basis sets & $\Delta \mathrm{H}_{\mathrm{o}}$ & $\Delta \mathrm{G}_{0}$ & $E_{a}$ & $\Delta \mathrm{G}^{\#}$ \\
\hline $6-31 G$ & -15.24 & -10.45 & 15.26 & 37.48 \\
\hline $6-311++(2 d, 2 p)$ & -12.83 & -8.01 & 15.68 & 41.28 \\
\hline
\end{tabular}

The mechanism of the reaction involves a transition state with the six-atom ring as described in Figure 3. The nitrogen atoms of the amine group approach from the carbon of the carboxylic acid and form a bond that links the two glycine molecules. The water molecule facilitates the exchange of the mobile proton of the nitrogen. Indeed, the solvent molecule pulls the hydrogen of the amine and releases its own hydrogen to the oxygen of the hydroxyl group of the carboxylic acid. It then becomes easy for the second water molecule to be released and the diglycine molecule is formed.

\section{Methanol assistance}


The explicit assistance of the diglycine formation with a methanol molecule decreased the heat of the reaction from $\Delta \mathrm{H}_{\mathrm{o}}$ equal $-12.63 \mathrm{kcal}^{\mathrm{mol}}{ }^{-1}$ to $-10.02 \mathrm{kcal}^{\mathrm{mol}}{ }^{-1}$ in gas phase. The reaction in the presence of methanol became more spontaneous to produce the dipeptide $\left(\Delta \mathrm{G}_{0}-9.02 \mathrm{kcal}^{\mathrm{mol}}{ }^{-1}\right)$. Kinetically, the energetic barrier of activation decreased by $2 \mathrm{kcal} . \mathrm{mol}^{-1}$ compared to its PCM homologue in the gas medium.

The mechanism of the peptide bond formation between the glycine molecules and assisted with a methanol molecule was very similar to the one proposed for the reaction in explicit water. Its corresponding transition state is also based on a 6-atom ring as depicted in Figure 5. The methanol molecule exchanges a hydrogen between the amine and the carboxylic acid groups. It is clear that the methanol plays the role of a catalyst because it participates in the mechanism, but it was not consumed at the end of the reaction. From the energetic barrier calculated at the same level of theory, the incorporation of a methanol molecule reduced this barrier by ca. $2 \mathrm{kcal}^{\mathrm{mol}}{ }^{-1}$ as shown in Table 4.

\begin{tabular}{|ccccc|}
\hline $\begin{array}{l}\text { Table 4. Thermodynamic and kinetic descriptors in the } \\
\text { explicitly assisted diglycine formation with } \mathrm{MeOH} \text { molecule } \\
\left.\text { (kcal.mol }{ }^{-1}\right)\end{array}$ \\
\hline Basis sets & $\Delta \mathrm{H}_{\mathrm{o}}$ & $\Delta \mathrm{G}_{0}$ & $\mathrm{E}_{\mathrm{a}}$ & $\Delta \mathrm{G}^{\#}$ \\
\hline $6-31 \mathrm{G}$ & -15.17 & -11.06 & 15.15 & 37.83 \\
$6-311++(2 \mathrm{~d}, 2 \mathrm{p})$ & -12.63 & -9.02 & 14.97 & 41.37 \\
\hline
\end{tabular}

Similar to water case, the explicit assistance with methanol molecule led to a transition state with the same distance between the nitrogen and the carbon involved in the peptide bond formation. The variation of distances in the 6-membered ring was illustrated in Figure 6.

\section{Cyclohexane assistance}

The diglycine formation in explicit cyclohexane solvent is exothermic with $\Delta \mathrm{H}_{0}$ equals to $-6.22 \mathrm{kcal} . \mathrm{mol}^{-}$ ${ }^{1}$, which is just $1 \mathrm{kcal}^{\mathrm{mol}}{ }^{-1}$ higher than the values calculated in PCM or in the gas conditions. In terms of free enthalpy of the reaction, the assistance with cyclohexane still allowed spontaneous peptide formation but it is close to zero $\left(\Delta \mathrm{G}_{0}-2.97 \mathrm{kcal}^{\mathrm{mol}}{ }^{-1}\right)$. This thermodynamic descriptor is equal to $-7.46 \mathrm{kcal}^{\mathrm{mol}}{ }^{-1}$ and $-7.86 \mathrm{kcal}^{\mathrm{mol}}{ }^{-1}$ in PCM (cyclohexane) and in gas, respectively. This reveals a more considerable difference when the cyclohexane was expressed explicitly.

The same trend was spotted when the activation energy was calculated in implicit and explicit solvent conditions and the gas state $\left(\Delta \mathrm{G}^{\#}\right.$ equal to $46 \mathrm{kcal} . \mathrm{mol}^{-1}$ in PCM and in gas, which is around half of what was measured when the explicit assistance with cyclohexane was employed).

\begin{tabular}{|ccccc|}
\hline $\begin{array}{l}\text { Table 5. Thermodynamic and kinetic descriptors in the } \\
\text { explicitly assisted diglycine formation with cyclohexane } \\
\text { molecule }\left(\mathrm{kcal} . \mathrm{mol}^{-1}\right)\end{array}$ \\
\hline Basis sets & $\Delta \mathrm{H}_{0}$ & $\Delta \mathrm{G}_{0}$ & $\mathrm{E}_{\mathrm{a}}$ & $\Delta \mathrm{G}^{\#}$ \\
\hline $6-31 \mathrm{G}$ & -5.48 & -3.47 & 44.57 & 85.82 \\
$6-311++(2 \mathrm{~d}, 2 \mathrm{p})$ & -6.22 & -2.97 & 44.20 & 85.68 \\
\hline
\end{tabular}

Although the Gibbs free energy of the reaction, depicted in Table 5, stated that the dipeptide formation is spontaneous in the presence of the explicit cyclohexane molecule $\left(\Delta G_{0}\right.$ equals $\left.-2.97 \mathrm{kcal}^{-\mathrm{mol}^{-1}}\right)$, this reaction seems to be kinetically not feasible as the free enthalpy of activation was $85 \mathrm{kcal}^{\mathrm{mol}}{ }^{-1}$ with both basis sets. This can be explained by the inherent stability of the bond in the non-polar cyclohexane and the difficulty to exchange hydrogen atoms with other molecules. The transition state illustrated between brackets in Figure 7 shows the same 6-atom ring that involves the mobile protons of the amine and the carboxylic acid and the proton belonging to the cyclohexane.

When dipeptide bond formation was assisted by an explicit cyclohexane molecule, the hydrogen covalently bonded to the cyclohexane was involved in the six-membered ring of the TS. Thus, the distances between the two closest hydrogens of cyclohexane to the glycine were D3 $=3.630 \AA$ and D4 $=$ 
$4.914 \AA$. During the transition state, these distances were reduced to $\mathrm{D} 9=1.465 \AA$ and $\mathrm{D} 10=1.611 \AA$ as shown in Figure 8. During the same transition phase, the $\mathrm{C}-\mathrm{O}$ and $\mathrm{N}-\mathrm{H}$ bond belonging to the transitioning ring were stretched.

The reaction profiles shown in Figure 9 differentiate between the formation of the dipeptide by the explicit assistance of water or by the implicit solvation with PCM model. The geometries of the solvated and the explicitly assisted transition states were examined in detail to explain the difference in their corresponding activation free enthalpies.

The structure of the water-solvated transition state is, in general, very close to the assisted one. Nevertheless, some differences in the involved interatomic distances were observed and illustrated in Figure 10. Therefore, the distance between the closest nitrogen to the first glycine and the carbon of the neighboring molecule as well as the $\mathrm{C}-\mathrm{O}$ distance of the second glycine were larger in the transition state's geometry in the implicit solvation assistance. Contrarily, the N-H distance of the first glycine was shorter.

The imaginary frequency associated with $\mathrm{TS}_{\text {solvated }}\left(\right.$ i.e. $475 \mathrm{icm}^{-1}$ ) is lower than that associated with $\mathrm{TS}_{\text {assisted }}$ (i.e. $966 \mathrm{i} \mathrm{cm}{ }^{-1}$ ). This is an additional element consistent with a higher activation barrier in the solvated TS case since the transition state zone of the influence of the formation of a solvated dipeptide bond and assisted by water were, respectively, equal to 3.89 and 2.48 au.

\section{Discussion}

Understanding the oligomerization mechanism of amino acids leading to the formation of peptides and proteins is a key step to uncover the origin of life. The instability of amino acids and the difficulty of their polymerization in aqueous solution present a major problem. Kekegawa and coworkers found that high pressure and $\mathrm{NH}_{3}$-rich environment stabilized glycine and alanine. ${ }^{[35]}$ In addition, glycine was discovered in samples of comet Wild 2 returned by NASA's Stardust spacecraft, which strengthens the argument that life in the universe may be common rather than rare. ${ }^{[36]}$ Electronic structure calculations based on the Density Functional Theory (DFT) were initially exploited to study the interaction between glycine and forsterite which is well-known cometary dust component. The chemisorption energy ranged from 58 to 96 $\mathrm{kcal} / \mathrm{mol}^{\left[{ }^{[37]}\right.}$ This range of energy is higher than what we found for the activation of the glycine condensation. On the one hand, this can be an indication that the chemical interaction with polar or nonpolar surfaces especially in comets can be the limiting factor to trigger the condensation. On the other hand, the rigid surface of forsterite can play the role of the heterogeneous catalyst by promoting the interactions between the carboxylic acid and the amine groups.

Although it was stated that the standard Gibbs energies condensation reactions of amino acid are uphill and the incorporation of geochemically produced condensing agents such as carbonyl sulfide, cyanamide, and polyphosphates was recommended to invert the unfavorable condensation Gibbs energies $^{[38]}$, we showed here that in the case of pure glycine the oligomerization is thermodynamically feasible and solvation reduces the activation energy required to ease the peptide bond formation.

Mathies et al. claimed that the radiation-induced, non-enzymatic formation of proteinogenic dipeptides in interstellar ice analogues is facile. This is a supplementary factor that is added to endorse the hypothesis of the diglycine formation in the catalyst-free environment.

A mineral catalyst such as hydroxyapatite also presented an alternative to harsh conditions of high temperature and pressure to promote peptide bond formation. Similar to protic solvents exploited in this work (i.e. water and methanol added explicitly in the neighborhood of glycine, the hydroxyapatite reduced the activation barrier for the formation of dipeptides by more than $50 \%$. The presence of this mineral compound or similar catalyst decreased the distance between amino and carboxyl groups on neighboring molecules and extends the contact time of the reaction group. ${ }^{[39]}$ 
André Brack reviewed the pathways from the interstellar amino acids to prebiotic catalytic peptides. ${ }^{[40]}$ For instance, the free enthalpy of condensation to form the dipeptide alanyl-glycine in $\mathrm{H}_{2} \mathrm{O}$ was 4.13 $\mathrm{kcal} / \mathrm{mol}$ at $37^{\circ} \mathrm{C}$ and $\mathrm{pH}$ 7. Comparing this Gibbs energy with the negative ones that we obtained for the glycine-glycine dipeptide condensation highlights the importance of the nature of amino acids that can undergo the exergonic condensation spontaneously. In our case, all the free energies obtained in the gas phase and in the presence of explicit solvent proved the exergonic character of the condensation and only the kinetic factor that is differentiating between the solvation environment. Therefore, the peptide bond formation in diglycine is mainly driven by the kinetic factors that can be overcome by the introduction of a homogeneous (i.e. By the utilization of an appropriate solvent or by autocatalysis) or a heterogeneous (i.e. In the case of physisorption and chemisorption with hydroxyapatite) catalyst.

\section{Conclusions}

Peptide bond formation in a glycine-glycine system was investigated and the effects of explicit and implicit solvent were studied. The solvents were introduced implicitly via the Polarized Continuum Model approach to include long-distance interactions. The introduction of discreet solvent molecules near the glycine residues focuses more on steric and short-distance non-covalent interactions. Four types of media were studied in this paper: the vacuum that imitates interstellar conditions, water and methanol as polar and protic solvents to show hydrogen bonding effects on the stabilization of the dipeptide system, and finally cyclohexane as a non-polar and aprotic solvent. The comparison of the energetic barrier of activation showed that methanol and water had a stabilizing effect on the transition state of the reaction and the mobile proton of these protic solvent facilitates the synthesis of the peptide kinetically. The study of the free energy of the reaction also demonstrated that peptide bond formation was spontaneous in all of the studied cases. In the absence of solvents (gas), the reaction was still similar to its homologues where the protic solvents were used. Cyclohexane was always the poorest solvent for promoting the reaction, demonstrating the importance of the mobile proton to leverage electronic exchange between the glycine molecules and the solvent. Both the explicit and implicit introduction of solvent effects have a crucial impact on the energetic descriptors of this reaction, thus both ought to be taken into consideration in order to account for both short distances interactions, such as hydrogen bonding and van der Waals interactions, and long-distance interactions, such as polarisability of the solvent.

\section{Acknowledgements}

We would like to thank Prof Tom K. Woo for providing some of the computational resources to run the calculation. We would like also to thank Dr Khaléd Essaleh for the valuable discussions.

Keywords: glycine, the origin of life, peptide, DFT, mechanism

\section{References and Notes}

[1] P. Redondo, C. Barrientos, A. Largo. Astrophys. J. 2013, 780, 181.

[2] P. Redondo, H. Martínez, Á. Cimas, C. Barrientos, A. Largo. Phys. Chem. Chem. Phys. 2013, $15,13005$.

[3] M. Rodriguez-Garcia, A. J. Surman, G. J. T. Cooper, I. Suárez-Marina, Z. Hosni, M. P. Lee, L. Cronin. Nat. Commun. 2015, 6, 1-7.

[4] H. Wincel, R. H. Fokkens. Rapid Commun. Mass Spectrom. 2002, 16 1, 15-26.

[5] E. Herbst. Annu. Rev. Phys. Chem. 1995, 46, 27-54.

[6] G. W. Cooper, J. R. Cronin. Geochim. Cosmochim. Acta 1995, 59, 1003-1015.

S. Yao, I. Ghosh, R. Zutshi, J. Chmielewski. Nature 1998, 396, 447-450.

[10] H. Frisch, Y. Nie, S. Raunser, P. Besenius. Chem. - A Eur. J. 2015, 21, 3304-3309.

[11] R. Issac, J. Chmielewski. J. Am. Chem. Soc. 2002.

[12] T. Li, K. C. Nicolaou. Nat. (London, United Kingdom) 1994, 369, 218-221.

[13] K. Severin, D. H. Lee, J. A. Martinez, M. R. Ghadiri. Chem. - A Eur. J. 1997, 3, 1017-1024. 
[14] A. Saghatelian, Y. Yokobayashi, K. Soltani, M. R. Ghadiri. Nature 2001, 409, 797-801.

[15] N. Vaidya, M. L. Manapat, I. A. Chen, R. Xulvi-Brunet, E. J. Hayden, N. Lehman. Nat. (London, United Kingdom) 2012, 491, 72-77.

[16] J. S. Griffith. Nature 1967, 215, 1043-1044.

[17] J.-M. Lehn. Sci. (Washington, DC, United States) 2002, 295, 2400-2403.

[18] J. K. Kumar, S. Gunasekaran, S. Loganathan, G. Anand, S. Kumaresan. Spectrochim. Acta Part A Mol. Biomol. Spectrosc. 2013, 115, 730-737.

[19] Y. Li, F. Li, Y. Zhu, X. Li, Z. Zhou, C. Liu, W. Zhang, M. Tang. Struct. Chem. 2016.

[20] P. D. Holtom, C. J. Bennett, Y. Osamura, N. J. Mason, R. I. Kaiser. Astrophys. J. 2005, 626, 940.

[21] J. H. Jensen, K. K. Baldridge, M. S. Gordon. J. Phys. Chem. 1992, 96, 8340-8351.

[22] D. Liu, T. Wyttenbach, C. J. Carpenter, M. T. Bowers. J. Am. Chem. Soc. 2004, 126, 3261-3270.

[23] S. Bhunia, A. Singh, A. K. Ojha. Eur. Phys. J. D 2016, 70, 106.

[24] E. Van Dornshuld, R. A. Vergenz, G. S. Tschumper. J. Phys. Chem. B 2014, 118, 8583-8590.

[25] F. R. Tortonda, J. L. Pascual-Ahuir, E. Silla, I. Tuñón. Chem. Phys. Lett. 1996, 260, 21-26.

[26] J. H. Jensen, M. S. Gordon. J. Am. Chem. Soc. 1995, 117, 8159-8170.

[27] D. Yanbo, K.-J. Karsten. J. Comput. Chem. 1998, 17, 338-349.

[28] H. Zou, Y. Hu, D. Xing. Chinese J. Chem. Phys. 2009, 22, 577-586.

[29] Y. Shi, Z. Zhou. J. Mol. Struct. THEOCHEM 2004, 674, 113-119.

[30] A. D. Becke. Phys. Rev. A 1988, 38, 3098-3100.

[31] C. Lee, W. Yang, R. G. Parr. Phys. Rev. B 1988, 37, 785-789.

[32] C. Gonzalez, H. B. Schlegel. J. Chem. Phys. 1991, 95, 5853-5860.

[33] M. J. Frisch, G. W. Trucks, H. B. Schlegel, G. E. Scuseria, M. A. Robb, J. R. Cheeseman, J. a. Montgomery, T. Vreven, K. N. Kudin, ... J. A. Pople. Gaussian 09 (Revision D.2), Gaussian, Inc., Pittsburgh, PA 2009.

[34] V. Barone, M. Cossi, J. Tomasi. J. Chem. Phys. 1997, 107, 3210-3221.

[35] T. Otake, T. Taniguchi, Y. Furukawa, F. Kawamura, H. Nakazawa, T. Kakegawa. Astrobiology 2011.

[36] S. A. Sandford, J. Aléon, C. M. O. D. Alexander, T. Araki, S. Bajt, G. A. Baratta, J. Borg, J. P. Bradley, D. E. Brownlee, ... M. E. Zolensky. Science (80-. ). 2006.

[37] E. Escamilla-Roa, F. Moreno. Planetary and Space Science. 2012.

[38] D. Ross, D. Deamer. Astrobiology 2019.

[39] J. Wu, Z. S. Zhang, X. W. Yu, H. H. Pan, W. G. Jiang, X. R. Xu, R. K. Tang. Chinese Sci. Bull. 2011.

[40] A. Brack. Chemistry and Biodiversity. 2007. 
GRAPHICAL ABSTRACT

Sofiene Achour, Zied Hosni, and Sarra Darghouthi,Christopher Syme

\section{Solvent effect on dipeptide bond formation: glycine as a case study}

Peptide bond formation is an important factor to understand the origin of life. Dipeptides are molecules made of two amino acids like the glycine. The effect of glycine solvation such as in water, methanol, and cyclohexane is investigated. Methanol is slightly better than water to leverage peptide bond formation. Energetic results in the gas environment are very close to those obtained in water, suggesting that peptide bonds can be formed under interstellar conditions.

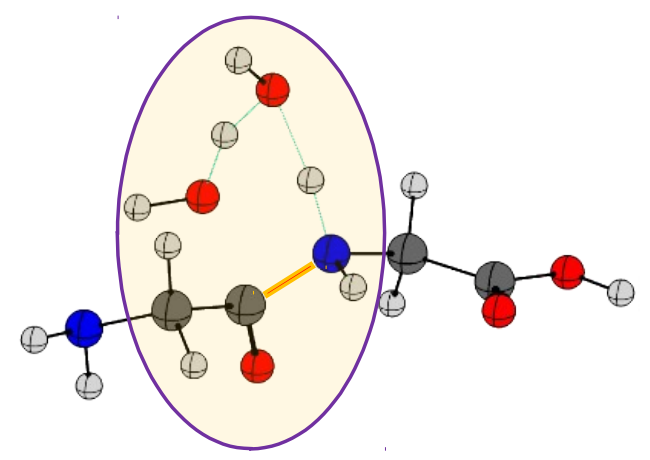


1 Sofiene Achour

University of Tunis El Manar, Research Unity of Modeling in Fundamental Sciences and Didactics, Team of Theoretical Chemistry and Reactivity, BP 254, El Manar 2, 2096, Tunisia

2 Zied Hosni

Strathclyde Institute of Pharmacy and Biomedical Sciences (SIPBS), University of Strathclyde, 161 Cathedral Street, Glasgow, U.K. G4 ORE

3 Sarra Darghouthi

University of Tunis El Manar, Research Unity of Modeling in Fundamental Sciences and Didactics, Team of Theoretical Chemistry and Reactivity, BP 254, El Manar 2, 2096, Tunisia

${ }^{4}$ Christopher Syme

MRC-University of Glasgow Centre for Virus Research, Sir Michael Stoker Building, Garscube Campus, 464 Bearsden Road, Glasgow, G61 1QH, Scotland, UK 
Solvents effect on dipeptide bond formation glycine as a ... (251.26 KiB) view on ChemRxiv • download file 


\title{
Solvent effect on dipeptide bond formation: glycine as a case study
}

\author{
Sofiene Achour, ${ }^{1}$ Zied Hosni, ${ }^{2}$ and Sarra Darghouthi, ${ }^{3}$ Christopher Syme ${ }^{4}$
}

Correspondence to: Zied Hosni (zied.hosni@strath.ac.uk)

\author{
${ }^{1}$ Sofiene Achour \\ University of Tunis EI Manar, Research Unity of Modeling in Fundamental Sciences and Didactics, Team of Theoretical \\ Chemistry and Reactivity, BP 254, El Manar 2, 2096, Tunisia \\ ${ }^{2}$ Zied Hosni \\ Strathclyde Institute of Pharmacy and Biomedical Sciences (SIPBS), University of Strathclyde, 161 Cathedral Street, \\ Glasgow, U.K. G4 ORE \\ ${ }^{3}$ Sarra Darghouthi \\ University of Tunis El Manar, Research Unity of Modeling in Fundamental Sciences and Didactics, Team of Theoretical \\ Chemistry and Reactivity, BP 254, El Manar 2, 2096, Tunisia \\ ${ }^{4}$ Christopher Syme \\ MRC-University of Glasgow Centre for Virus Research, Sir Michael Stoker Building, Garscube Campus, 464 Bearsden \\ Road, Glasgow, G61 1QH, Scotland, UK
}

\begin{abstract}
Peptide bond formation is a crucial chemical process that dominates most biological mechanisms and is claimed to be a governing factor in the origin of life. Dipeptides made from glycine are studied computationally via Density Functional Theory (DFT) using two different basis sets. This reaction was investigated from both a thermodynamic and kinetic point of view. The effect of explicit solvation via the introduction of discreet solvent molecules was investigated. Water, methanol, and cyclohexane were all employed as solvent media in addition to gas to investigate their effects on the mechanism of peptide bond formation. This computational investigation revealed that methanol is slightly better than water to leverage peptide bond formation both kinetically and thermodynamically, while cyclohexane, a non-polar and non-protic solvent, is the least effective after gas as a medium of solvation. Energetic results in the gas environment are very close to those obtained in polar and protic solvents, suggesting that peptide bonds can be formed under interstellar conditions.
\end{abstract}

\section{Introduction}

Peptide bond formation is a vital process that has attracted the attention of the scientific community as it is a key concept in understanding the origin of life. This exceptional type of chemical bond is required in any biological mechanism that involves amino acid interactions and the formation of biomolecules under prebiotic conditions. ${ }^{[1,2]}$ Since the beginning of the $20^{\text {th }}$ century, polypeptides of various types and structures have been synthesised. Although several attempts were carried out in the aim of forming peptide bonds with high yield, these reactions usually require activated amino-acid precursors and heterogeneous supports. ${ }^{[3]}$ The synthesis of peptides has also been performed in the gas phase such as in the case of ionmolecule reactions containing methionine and glutamic acid. ${ }^{[4]}$ The peptide bond formation in this particular medium is extremely relevant in astro-chemistry because it enables the study of prebiotic molecular synthesis in the interstellar medium. ${ }^{[5]}$ A radiochemical search revealed the presence of the simplest amino acid, glycine, and many amino acids have been isolated in different meteorites. ${ }^{[6]}$ Although simple entities such as $\mathrm{H} 2, \mathrm{CO}, \mathrm{HCN}$ were more abundant, biological building blocks such as the simplest amino acids were spotted in interstellar ice together with methanol, ammonia and hydrogen cyanide. ${ }^{[7]}$ 
Several studies have demonstrated that peptides can self-replicate under certain conditions. ${ }^{[8-17]}$ The simplest example of peptide bond formation involves two glycine molecules via the following condensation reaction:

$$
\text { 2Gly -> Gly-Gly + H2O }
$$

Glycine has the peculiarity of lacking a chiral centre and is therefore optically inactive. Its neutral form is generally favoured in the gas phase, while its zwitterionic form is favoured in solution and in the solid state ${ }^{[18]} \mathrm{Li}$ and coworkers studied the solvent effects on the cyclisation of dipeptide from neutral monomers. ${ }^{[19]}$ Numerous computational studies have been conducted to investigate the formation mechanism of glycine through a radical-radical reaction involving $\mathrm{t}-\mathrm{HOCO}$ and $\mathrm{CH}_{2} \mathrm{NH}_{2}{ }^{[20]}$ Jensen et al. were interested in the uncatalysed stepwise and concerted routes of peptide bond formation. The authors explained the effect of the entropy and the electronic structures of the transition state (TS) on the energetic barrier heights controlling this reaction. ${ }^{21]}$

Noncovalent interactions in diglycine and diglycine-water models were investigated computationally by Liu and coworkers. They indicated that the first water molecule binds simultaneously to both oxygen atoms of the carboxylate forming two loose $\mathrm{H}$-bonds. ${ }^{[22]}$ It was revealed by Bhunia et al., that the kinetic preference and the concerted/stepwise mechanism is very sensitive to the level of theory that has been used. For instance, B3LYP/6-31G(d,p) favoured the concerted route to form the peptide bond. Whereas, it was the stepwise route that was dominant when the M062X/6-31G(d,p) level of theory was used. ${ }^{[23]}$

Van Dornshuld et al. highlighted the stabilising effect of a water molecule on the cis and trans products of the condensation via the hydrogen bonds by $5-9 \mathrm{kcal}^{\mathrm{mol}}{ }^{-1}{ }^{[24]}$ Therefore, it is clear that solvent interactions have a drastic effect on the condensation process. This has been investigated computationally by implicitly surrounding the glycine within a cavity of continuum defined by macroscopic properties such as the dielectric constant. This approach represents properly nonspecific and long-range interactions. A second approach is available and consists of adding one or more discrete solvent molecules. This method targets, generally, to spot the catalytic actions and the specific effects of the solvent. ${ }^{[25]}$ The number of explicit solvent molecules required to stabilize glycine is still not clear. For example, Jensen and Gordon used MP2 calculations on structures optimized at the HF level of theory and included diffuse and polarization functions for the basis set. They claimed that at least two water molecules are required to stabilize the glycine zwitterion. ${ }^{[26]}$ Whereas, Ding and Krogh-Jespersen found that one molecule of water is sufficient to stabilize glycine at the same level of theory and by exploiting a 6-31G basis set with polarization and diffuse functions in some atoms. ${ }^{[27]}$ Tortonda and coworkers studied the stabilization of neutral glycine with an explicit water molecule with MP2 calculation and found that the zwitterionic form cannot be stabilized by a single water entity. The same authors concluded that for this type of system, the discrete and continuum solvent models are complementary to explain water-glycine interactions and found that several explicit water molecules did not affect the mechanism of the concerted zwitterion formation. ${ }^{[25]}$ Zou et al. investigated the microsolvation of the glycine in the presence of different number of explicit methanol molecule via DFT calculations. They found that the zwitterionic form can be stabilized by one methanol entity. If two or three methanol molecules are involved, they tend to be located near the carboxylic acid group of the neutral form of glycine. A bridge of methanol forms between the acid and the amino group in the zwitterionic case. When five or six methanols are employed, the zwitterionic and the neutral form of glycine tend to be isoenergetic. The authors concluded that up to nine methanols are required to fully solvate a glycine molecule. ${ }^{[28]} \mathrm{Ab}$ initio, MP2 and B3LYP were all exploited with different basis sets to study the interaction between glycine and hydrogen peroxide. The authors stated that the stability of the solventglycine complex is sensitive to the selected glycine conformation. ${ }^{[29]}$

In this paper, we investigate the thermodynamic and kinetic mechanism of peptide bond formation for glycine in polar and non-polar solvents that are defined both implicitly and explicitly. The molecules of water, methanol and cyclohexane studied here play the role of solvents and also the catalyst for the dipeptide formation when their concentration is low and the probability of collision with the amino acid is less frequent. The results of these mechanisms are compared with those obtained in vacuum. 


\section{Computational method}

Density functional theory (DFT) was employed at B3LYP level of theory and with the simple 6-31G(d,p) and the extended 6-311++(2d,2p) (i.e. with double polarization and diffuse basis sets) for a better explanation of non-covalent bonds and solvent effects. The B3LYP functional is a combination of Becke's three parameters functional and nonlocal correlation provided by Lee, Yang and Parr (LYP). ${ }^{[30,31]}$ This method is relevant to simulate organic reactions and transition states. The same level of theory was kept to perform harmonic vibrational calculations with the two basis sets for each case in order to confirm the presence of one imaginary frequency in the case of a transition state and the absence of imaginary frequencies for the optimized structures at their energetic minima. The Berny algorithm was employed to optimize the structure of interest to a transition state. Intrinsic reaction coordinate calculations followed each optimization of the reactant, product and transition state to check the connection of the latter to the right minima. ${ }^{[32]}$ The Gibbs free energy was employed to evaluate the kinetic factor instead of the electronic energy difference from the IRC plots. All calculations were carried out using the Gaussian 09 package. ${ }^{[33]}$

Only the concerted pathway leading to the trans isomer was considered in this study because it was demonstrated that this configuration is favored thermodynamically (exothermic by ca. $5 \mathrm{kcal}^{\mathrm{mol}}{ }^{-1}$ ) and kinetically (barrier height $\approx 32 \mathrm{kcal} . \mathrm{mol}^{-1}$ and ca. $8 \mathrm{kcal} \cdot \mathrm{mol}^{-1}$ than the concerted cis pathway) according to

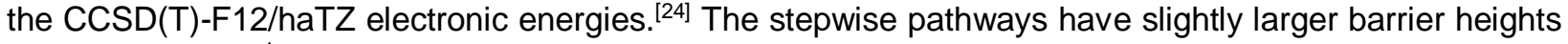
(by 4-8 kcal. $\mathrm{mol}^{-1}$ ). Solvent effects were included explicitly by adding a molecule of solvent to the reaction between the two glycines or implicitly by exploiting the Polarizable Continuum Model (PCM) that is based on the calculation of the molecular free energy in solution as the sum over three terms:

$$
G_{\text {sol }}=G_{e s}+G_{d r}+G_{c a v}
$$

These components represent the electrostatic (es) and the dispersion-repulsion (dr) contributions to the free energy, and the cavitation energy (cav) through interlocking van der Waals spheres centred at atomic positions. ${ }^{[34]}$

\section{Results}

\section{Non-explicitly assisted dipeptide formation}

The comparison between the reaction enthalpy in gas and in Polarized Continuum Model reveals that the formation of the peptide bond is exothermic in all the cases. The reaction was more exothermic in polar solvents such as in water and methanol. This can be quantitatively correlated to the dielectric constant, the dipole moment and the van der Waals volume of the solvents of interest. For instance, water and methanol have a dipole moment equal to $1.85 \mathrm{D}$ and $1.7 \mathrm{D}$, respectively. Conversely, the dipole moment of cyclohexane is nil. The reaction in the implicit solvent and in gas was spontaneous, too. Indeed, $\Delta G_{0}$ equaled approximately $-9 \mathrm{kcal}^{\mathrm{mol}}{ }^{-1}$ in both cases. Kinetically, Table 1 shows that the energetic barrier was $46.11 \mathrm{kcal}^{\mathrm{mol}}{ }^{-1}$ in gas with the extended basis set and $44.38 \mathrm{kcal}^{\mathrm{mol}}{ }^{-1}$ in water, which leads to the conclusion that these types of media had no significant effect on the rate of the reaction. The utilization of the simple $(6-31 G)$ or the extended $(6-311++(2 d, 2 p))$ basis set gave similar results for all the thermodynamic descriptors. Indeed, the energetic difference did not exceed $2 \mathrm{kcal} . \mathrm{mol}^{-1}$.

The IRC approach to determine the path of the chemical reaction between two glycines suggested the formation of a 4 membered atomic ring in the transition state as illustrated in Figure 1. The suggested mechanism is illustrated in Figure 2. It starts with the positioning of the carboxylic functional group in proximity to its amine homologue. In a concerted way, a bridge is formed between the two molecules through the carbon atoms of the carboxylic acid and the nitrogen of the amine group. Simultaneously, the hydroxyl group linked to the carbon is liberated in the form of water after withdrawing the mobile hydrogen atom that was connected to the nitrogen of the amine function.

\begin{tabular}{l}
$\begin{array}{l}\text { Table 1. Thermodynamic and kinetic descriptors in the } \\
\text { explicitly non-assisted diglycine formation in gas in } \\
\text { (kcal.mol }{ }^{-1} \text { ) }\end{array}$ \\
\hline Basis sets \\
\hline
\end{tabular}




\begin{tabular}{|ccccc|}
\hline $6-31 \mathrm{G}$ & -7.8 & -8 & 27.76 & 44.95 \\
$6-311++(2 \mathrm{~d}, 2 \mathrm{p})$ & -7.48 & -7.86 & 27.70 & 46.11 \\
\hline
\end{tabular}

The comparison of the structures of reagents, products and transition states revealed that the distance between the closest nitrogen of the first glycine and the carbon of the neighbouring molecule decreased from $\mathrm{D} 1=3.391 \AA$ to $\mathrm{D} 5=1.604 \AA$ during the TS. This distance was stabilized to $\mathrm{D} 9=1.353 \AA$ when the product was formed. By the same scenario, the dihedral angle between the $\mathrm{C}-\mathrm{N}$ bond of the first glycine and the $\mathrm{C}-\mathrm{C}$ bond of the second glycine increased progressively from $\mathrm{DA} 1=114.83^{\circ}$ at the starting point to $\mathrm{DA} 2=137.28^{\circ}$ in the TS structure and finally to $\mathrm{DA} 3=177.82^{\circ}$ in the product. It is noteworthy that during the transition state, the distance between the nitrogen approaching from the other glycine started to lose the link with its hydrogen. Therefore, the distance of the $\mathrm{N}-\mathrm{H}$ was $\mathrm{D} 4=1.011 \AA$ in the reagent then increased to $\mathrm{D} 8=1.156 \AA$.

\begin{tabular}{|c|c|c|c|c|c|}
\hline $\begin{array}{c}\text { Non } \\
\text { assisted } \\
\text { media }\end{array}$ & $\begin{array}{l}\text { Basis } \\
\text { sets }\end{array}$ & $\Delta \mathrm{H}_{0}$ & $\Delta \mathrm{G}_{0}$ & $\mathrm{E}_{\mathrm{a}}$ & $\Delta \mathrm{G}^{\#}$ \\
\hline in PCM & A & -10.65 & -9.1 & 28 & 42.46 \\
\hline (water) & B & -10.04 & -7.6 & 29.40 & 44.38 \\
\hline in $\mathrm{PCM}$ & A & -10.62 & -9.2 & 27.61 & 42.5 \\
\hline$(\mathrm{MeOH})$ & B & -10.02 & -8.79 & 29.00 & 43.34 \\
\hline in PCM & A & -9.18 & -8.8 & 26.40 & 44.29 \\
\hline$\left(\mathrm{C}_{6} \mathrm{H}_{6}\right)$ & B & -7.87 & -7.46 & 26.55 & 46.4 \\
\hline
\end{tabular}

Similarly, in the other glycine, the C-O moiety involved in peptide bond formation was dissociated progressively from its corresponding molecule and migrates to form a water molecule with the hydrogen dissociated from the nitrogen of the neighbouring molecule in the case of the gas phase. Thus, D2 increased from $1.357 \AA$ in the reagent to $D 6=1.913 \AA$ in the transition state. The glycine reaction was also investigated with PCM solvation model, which revealed that the activation energy obtained in gas phase is very close the ones obtained with the implicit solvation and depicted in Table 2.

\section{Explicitly solvent-assisted dipeptide formation}

\section{Water assistance}

When a water molecule was introduced explicitly to leverage the formation of the peptide bond, one could follow the migration of atoms between the two glycine molecules and the electronic exchange through the water molecule. The five distances that were used to monitor this mechanism are summarized in the table that joins Figure 4. D2 to D6 and D8 to D12 showed the distances between the six atoms that were involved in the reaction at the starting point and at the TS, respectively. The peptide bond was slightly longer at the TS with water assistance comparing to gas medium reaction.

Peptide bond formation is exothermic in water with a $\Delta \mathrm{H}_{0}$ equal to $-12.83 \mathrm{kcal} . \mathrm{mol}^{-1}$ with the extended basis set and the water molecule expressed explicitly with the glycines. This reaction is spontaneous for the peptide under the same conditions. Therefore, $\Delta G_{0}$ is equal to $-8.01 \mathrm{kcal} . \mathrm{mol}^{-1}$ and $-7.6 \mathrm{kcal}^{\mathrm{mol}}{ }^{-1}$, respectively, in explicit and implicit water solvent at the extended basis set. When the water molecule was defined explicitly, the energetic barrier depicted in Table 3 was $3.1 \mathrm{kcal}^{-\mathrm{mol}^{-1}}$ lower than its homologue in $\mathrm{PCM}\left(\Delta \mathrm{G}^{\#}\right.$ equals $41.28 \mathrm{kcal} . \mathrm{mol}^{-1}$ in the explicitly assisted reaction). 


\begin{tabular}{|ccccc|}
\hline $\begin{array}{l}\text { Table 3. Thermodynamic and kinetic descriptors in the } \\
\text { explicitly assisted diglycine formation with water molecule } \\
\left.\text { (kcal.mol }{ }^{-1}\right)\end{array}$ \\
\hline Basis sets & $\Delta \mathrm{H}_{0}$ & $\Delta \mathrm{G}_{0}$ & $\mathrm{E}_{\mathrm{a}}$ & $\Delta \mathrm{G}^{\#}$ \\
\hline $6-31 \mathrm{G}$ & -15.24 & -10.45 & 15.26 & 37.48 \\
$6-311++(2 \mathrm{~d}, 2 \mathrm{p})$ & -12.83 & -8.01 & 15.68 & 41.28 \\
\hline
\end{tabular}

The mechanism of the reaction involves a transition state with the six-atom ring as described in Figure 3. The nitrogen atoms of the amine group approach from the carbon of the carboxylic acid and form a bond that links the two glycine molecules. The water molecule facilitates the exchange of the mobile proton of the nitrogen. Indeed, the solvent molecule pulls the hydrogen of the amine and releases its own hydrogen to the oxygen of the hydroxyl group of the carboxylic acid. It then becomes easy for the second water molecule to be released and the diglycine molecule is formed.

\section{Methanol assistance}

The explicit assistance of the diglycine formation with a methanol molecule decreased the heat of the reaction from $\Delta \mathrm{H}_{0}$ equal $-12.63 \mathrm{kcal}^{\mathrm{mol}}{ }^{-1}$ to $-10.02 \mathrm{kcal} \mathrm{mol}^{-1}$ in gas phase. The reaction in the presence of methanol became more spontaneous to produce the dipeptide $\left(\Delta \mathrm{G}_{0}-9.02 \mathrm{kcal}^{-\mathrm{mol}^{-1}}\right)$. Kinetically, the energetic barrier of activation decreased by $2 \mathrm{kcal} \cdot \mathrm{mol}^{-1}$ compared to its PCM homologue in the gas medium.

The mechanism of the peptide bond formation between the glycine molecules and assisted with a methanol molecule was very similar to the one proposed for the reaction in explicit water. Its corresponding transition state is also based on a 6-atom ring as depicted in Figure 5. The methanol molecule exchanges a hydrogen between the amine and the carboxylic acid groups. It is clear that the methanol plays the role of a catalyst because it participates in the mechanism, but it was not consumed at the end of the reaction. From the energetic barrier calculated at the same level of theory, the incorporation of a methanol molecule reduced this barrier by ca. $2 \mathrm{kcal}^{\mathrm{mol}}{ }^{-1}$ as shown in Table 4.

\begin{tabular}{|ccccc|}
\hline $\begin{array}{l}\text { Table 4. Thermodynamic and kinetic descriptors in the } \\
\text { explicitly assisted diglycine formation with } \mathrm{MeOH} \text { molecule } \\
\text { (kcal.mol }^{-1} \text { ) }\end{array}$ \\
\hline Basis sets & $\Delta \mathrm{H}_{0}$ & $\Delta \mathrm{G}_{0}$ & $\mathrm{E}_{\mathrm{a}}$ & $\Delta \mathrm{G}^{\#}$ \\
\hline $6-31 \mathrm{G}$ & -15.17 & -11.06 & 15.15 & 37.83 \\
$6-311++(2 \mathrm{~d}, 2 \mathrm{p})$ & -12.63 & -9.02 & 14.97 & 41.37 \\
\hline
\end{tabular}

Similar to water case, the explicit assistance with methanol molecule led to a transition state with the same distance between the nitrogen and the carbon involved in the peptide bond formation. The variation of distances in the 6-membered ring was illustrated in Figure 6.

\section{Cyclohexane assistance}

The diglycine formation in explicit cyclohexane solvent is exothermic with $\Delta \mathrm{H}_{0}$ equals to $-6.22 \mathrm{kcal}^{-m o l}$ ${ }^{1}$, which is just $1 \mathrm{kcal}^{\mathrm{mol}}{ }^{-1}$ higher than the values calculated in PCM or in the gas conditions. In terms of free enthalpy of the reaction, the assistance with cyclohexane still allowed spontaneous peptide formation but it is close to zero $\left(\Delta \mathrm{G}_{0}-2.97 \mathrm{kcal} . \mathrm{mol}^{-1}\right)$. This thermodynamic descriptor is equal to $-7.46 \mathrm{kcal} . \mathrm{mol}^{-1}$ and $-7.86 \mathrm{kcal}^{\mathrm{mol}}{ }^{-1}$ in PCM (cyclohexane) and in gas, respectively. This reveals a more considerable difference when the cyclohexane was expressed explicitly.

The same trend was spotted when the activation energy was calculated in implicit and explicit solvent conditions and the gas state ( $\Delta \mathrm{G}^{\#}$ equal to $46 \mathrm{kcal}^{\mathrm{mol}}{ }^{-1}$ in PCM and in gas, which is around half of what was measured when the explicit assistance with cyclohexane was employed). 


\begin{tabular}{|ccccc|}
\hline $\begin{array}{l}\text { Table 5. Thermodynamic and kinetic descriptors in the } \\
\text { explicitly assisted diglycine formation with cyclohexane } \\
\text { molecule }\left(\mathrm{kcal}_{\mathrm{mol}}^{-1}\right)\end{array}$ \\
\hline Basis sets & $\Delta \mathrm{H}_{0}$ & $\Delta \mathrm{G}_{0}$ & $\mathrm{E}_{\mathrm{a}}$ & $\Delta \mathrm{G}^{\#}$ \\
\hline $6-31 \mathrm{G}$ & -5.48 & -3.47 & 44.57 & 85.82 \\
$6-311++(2 \mathrm{~d}, 2 \mathrm{p})$ & -6.22 & -2.97 & 44.20 & 85.68 \\
\hline
\end{tabular}

Although the Gibbs free energy of the reaction, depicted in Table 5, stated that the dipeptide formation is spontaneous in the presence of the explicit cyclohexane molecule $\left(\Delta \mathrm{G}_{0}\right.$ equals $\left.-2.97 \mathrm{kcal} . \mathrm{mol}^{-1}\right)$, this reaction seems to be kinetically not feasible as the free enthalpy of activation was $85 \mathrm{kcal}^{\mathrm{mol}}{ }^{-1}$ with both basis sets. This can be explained by the inherent stability of the bond in the non-polar cyclohexane and the difficulty to exchange hydrogen atoms with other molecules. The transition state illustrated between brackets in Figure 7 shows the same 6-atom ring that involves the mobile protons of the amine and the carboxylic acid and the proton belonging to the cyclohexane.

When dipeptide bond formation was assisted by an explicit cyclohexane molecule, the hydrogen covalently bonded to the cyclohexane was involved in the six-membered ring of the TS. Thus, the distances between the two closest hydrogens of cyclohexane to the glycine were D3 $=3.630 \AA$ and D4 $=4.914 \AA$. During the transition state, these distances were reduced to $D 9=1.465 \AA$ and $D 10=1.611 \AA$ as shown in Figure 8. During the same transition phase, the $\mathrm{C}-\mathrm{O}$ and $\mathrm{N}-\mathrm{H}$ bond belonging to the transitioning ring were stretched.

The reaction profiles shown in Figure 9 differentiate between the formation of the dipeptide by the explicit assistance of water or by the implicit solvation with PCM model. The geometries of the solvated and the explicitly assisted transition states were examined in detail to explain the difference in their corresponding activation free enthalpies.

The structure of the water-solvated transition state is, in general, very close to the assisted one. Nevertheless, some differences in the involved interatomic distances were observed and illustrated in Figure 10. Therefore, the distance between the closest nitrogen to the first glycine and the carbon of the neighboring molecule as well as the $\mathrm{C}$-O distance of the second glycine were larger in the transition state's geometry in the implicit solvation assistance. Contrarily, the $\mathrm{N}-\mathrm{H}$ distance of the first glycine was shorter.

The imaginary frequency associated with $\mathrm{TS}_{\text {solvated }}$ (i.e. $475 \mathrm{icm}^{-1}$ ) is lower than that associated with TS $_{\text {assisted }}$ (i.e. $966 \mathrm{i} \mathrm{cm}^{-1}$ ). This is an additional element consistent with a higher activation barrier in the solvated TS case since the transition state zone of the influence of the formation of a solvated dipeptide bond and assisted by water were, respectively, equal to 3.89 and 2.48 au.

\section{Discussion}

Understanding the oligomerization mechanism of amino acids leading to the formation of peptides and proteins is a key step to uncover the origin of life. The instability of amino acids and the difficulty of their polymerization in aqueous solution present a major problem. Kekegawa and coworkers found that high pressure and $\mathrm{NH}_{3}$-rich environment stabilized glycine and alanine. ${ }^{[35]}$ In addition, glycine was discovered in samples of comet Wild 2 returned by NASA's Stardust spacecraft, which strengthens the argument that life in the universe may be common rather than rare. ${ }^{[36]}$ Electronic structure calculations based on the Density Functional Theory (DFT) were initially exploited to study the interaction between glycine and forsterite which is well-known cometary dust component. The chemisorption energy ranged from 58 to $96 \mathrm{kcal} / \mathrm{mol} .{ }^{[37]}$ This range of energy is higher than what we found for the activation of the glycine condensation. On the one hand, this can be an indication that the chemical interaction with polar or non-polar surfaces especially in comets can be the limiting factor to trigger the condensation. On the other hand, the rigid surface of forsterite can play the role of the heterogeneous catalyst by promoting the interactions between the carboxylic acid and the amine groups. 
Although it was stated that the standard Gibbs energies condensation reactions of amino acid are uphill and the incorporation of geochemically produced condensing agents such as carbonyl sulfide, cyanamide, and polyphosphates was recommended to invert the unfavorable condensation Gibbs energies ${ }^{[38]}$, we showed here that in the case of pure glycine the oligomerization is thermodynamically feasible and solvation reduces the activation energy required to ease the peptide bond formation.

Mathies et al. claimed that the radiation-induced, non-enzymatic formation of proteinogenic dipeptides in interstellar ice analogues is facile. This is a supplementary factor that is added to endorse the hypothesis of the diglycine formation in the catalyst-free environment.

A mineral catalyst such as hydroxyapatite also presented an alternative to harsh conditions of high temperature and pressure to promote peptide bond formation. Similar to protic solvents exploited in this work (i.e. water and methanol added explicitly in the neighborhood of glycine, the hydroxyapatite reduced the activation barrier for the formation of dipeptides by more than $50 \%$. The presence of this mineral compound or similar catalyst decreased the distance between amino and carboxyl groups on neighboring molecules and extends the contact time of the reaction group. ${ }^{[39]}$

André Brack reviewed the pathways from the interstellar amino acids to prebiotic catalytic peptides. ${ }^{[40]}$ For instance, the free enthalpy of condensation to form the dipeptide alanyl-glycine in $\mathrm{H}_{2} \mathrm{O}$ was 4.13 $\mathrm{kcal} / \mathrm{mol}$ at $37^{\circ} \mathrm{C}$ and $\mathrm{pH} 7$. Comparing this Gibbs energy with the negative ones that we obtained for the glycine-glycine dipeptide condensation highlights the importance of the nature of amino acids that can undergo the exergonic condensation spontaneously. In our case, all the free energies obtained in the gas phase and in the presence of explicit solvent proved the exergonic character of the condensation and only the kinetic factor that is differentiating between the solvation environment. Therefore, the peptide bond formation in diglycine is mainly driven by the kinetic factors that can be overcome by the introduction of a homogeneous (i.e. By the utilization of an appropriate solvent or by autocatalysis) or a heterogeneous (i.e. In the case of physisorption and chemisorption with hydroxyapatite) catalyst.

\section{Conclusions}

Peptide bond formation in a glycine-glycine system was investigated and the effects of explicit and implicit solvent were studied. The solvents were introduced implicitly via the Polarized Continuum Model approach to include long-distance interactions. The introduction of discreet solvent molecules near the glycine residues focuses more on steric and short-distance non-covalent interactions. Four types of media were studied in this paper: the vacuum that imitates interstellar conditions, water and methanol as polar and protic solvents to show hydrogen bonding effects on the stabilization of the dipeptide system, and finally cyclohexane as a non-polar and aprotic solvent. The comparison of the energetic barrier of activation showed that methanol and water had a stabilizing effect on the transition state of the reaction and the mobile proton of these protic solvent facilitates the synthesis of the peptide kinetically. The study of the free energy of the reaction also demonstrated that peptide bond formation was spontaneous in all of the studied cases. In the absence of solvents (gas), the reaction was still similar to its homologues where the protic solvents were used. Cyclohexane was always the poorest solvent for promoting the reaction, demonstrating the importance of the mobile proton to leverage electronic exchange between the glycine molecules and the solvent. Both the explicit and implicit introduction of solvent effects have a crucial impact on the energetic descriptors of this reaction, thus both ought to be taken into consideration in order to account for both short distances interactions, such as hydrogen bonding and van der Waals interactions, and longdistance interactions, such as polarisability of the solvent.

\section{Acknowledgements}

We would like to thank Prof Tom K. Woo for providing some of the computational resources to run the calculation. We would like also to thank Dr Khaléd Essaleh for the valuable discussions.

Keywords: glycine, the origin of life, peptide, DFT, mechanism 


\section{References and Notes}

[1] P. Redondo, C. Barrientos, A. Largo. Astrophys. J. 2013, 780, 181.

[2] P. Redondo, H. Martínez, Á. Cimas, C. Barrientos, A. Largo. Phys. Chem. Chem. Phys. 2013, $15,13005$.

[3] M. Rodriguez-Garcia, A. J. Surman, G. J. T. Cooper, I. Suárez-Marina, Z. Hosni, M. P. Lee, L. Cronin. Nat. Commun. 2015, 6, 1-7.

[4] H. Wincel, R. H. Fokkens. Rapid Commun. Mass Spectrom. 2002, 16 1, 15-26.

[5] E. Herbst. Annu. Rev. Phys. Chem. 1995, 46, 27-54.

[6] G. W. Cooper, J. R. Cronin. Geochim. Cosmochim. Acta 1995, 59, 1003-1015. M. P. Bernstein, J. P. Dworkin, S. A. Sandford, G. W. Cooper, L. J. Allamandola. Nature 2002, 416, $401-403$. Y. Ogata, E. Imai, H. Honda, K. Hatori, K. Matsuno. Orig. Life Evol. Biosph. 2000, 30, 527-537. S. Yao, I. Ghosh, R. Zutshi, J. Chmielewski. Nature 1998, 396, 447-450.

H. Frisch, Y. Nie, S. Raunser, P. Besenius. Chem. - A Eur. J. 2015, 21, 3304-3309. R. Issac, J. Chmielewski. J. Am. Chem. Soc. 2002. T. Li, K. C. Nicolaou. Nat. (London, United Kingdom) 1994, 369, 218-221. K. Severin, D. H. Lee, J. A. Martinez, M. R. Ghadiri. Chem. - A Eur. J. 1997, 3, 1017-1024.

A. Saghatelian, Y. Yokobayashi, K. Soltani, M. R. Ghadiri. Nature 2001, 409, 797-801.

[15] N. Vaidya, M. L. Manapat, I. A. Chen, R. Xulvi-Brunet, E. J. Hayden, N. Lehman. Nat. (London, United Kingdom) 2012, 491, 72-77.

[16] J. S. Griffith. Nature 1967, 215, 1043-1044.

[17] J.-M. Lehn. Sci. (Washington, DC, United States) 2002, 295, 2400-2403.

[18] J. K. Kumar, S. Gunasekaran, S. Loganathan, G. Anand, S. Kumaresan. Spectrochim. Acta Part A Mol. Biomol. Spectrosc. 2013, 115, 730-737.

[19] Y. Li, F. Li, Y. Zhu, X. Li, Z. Zhou, C. Liu, W. Zhang, M. Tang. Struct. Chem. 2016.

[20] P. D. Holtom, C. J. Bennett, Y. Osamura, N. J. Mason, R. I. Kaiser. Astrophys. J. 2005, 626, 940.

[21] J. H. Jensen, K. K. Baldridge, M. S. Gordon. J. Phys. Chem. 1992, 96, 8340-8351.

[22] D. Liu, T. Wyttenbach, C. J. Carpenter, M. T. Bowers. J. Am. Chem. Soc. 2004, 126, 3261-3270.

[23] S. Bhunia, A. Singh, A. K. Ojha. Eur. Phys. J. D 2016, 70, 106.

[24] E. Van Dornshuld, R. A. Vergenz, G. S. Tschumper. J. Phys. Chem. B 2014, 118, 8583-8590.

[25] F. R. Tortonda, J. L. Pascual-Ahuir, E. Silla, I. Tuñón. Chem. Phys. Lett. 1996, 260, 21-26.

[26] J. H. Jensen, M. S. Gordon. J. Am. Chem. Soc. 1995, 117, 8159-8170.

[27] D. Yanbo, K.-J. Karsten. J. Comput. Chem. 1998, 17, 338-349.

[28] H. Zou, Y. Hu, D. Xing. Chinese J. Chem. Phys. 2009, 22, 577-586.

[29] Y. Shi, Z. Zhou. J. Mol. Struct. THEOCHEM 2004, 674, 113-119.

[30] A. D. Becke. Phys. Rev. A 1988, 38, 3098-3100.

[31] C. Lee, W. Yang, R. G. Parr. Phys. Rev. B 1988, 37, 785-789.

[32] C. Gonzalez, H. B. Schlegel. J. Chem. Phys. 1991, 95, 5853-5860.

[33] M. J. Frisch, G. W. Trucks, H. B. Schlegel, G. E. Scuseria, M. A. Robb, J. R. Cheeseman, J. a. Montgomery, T. Vreven, K. N. Kudin, ... J. A. Pople. Gaussian 09 (Revision D.2), Gaussian, Inc., Pittsburgh, PA 2009.

[34] V. Barone, M. Cossi, J. Tomasi. J. Chem. Phys. 1997, 107, 3210-3221.

[35] T. Otake, T. Taniguchi, Y. Furukawa, F. Kawamura, H. Nakazawa, T. Kakegawa. Astrobiology 2011.

[36] S. A. Sandford, J. Aléon, C. M. O. D. Alexander, T. Araki, S. Bajt, G. A. Baratta, J. Borg, J. P. Bradley, D. E. Brownlee, ... M. E. Zolensky. Science (80-. ). 2006.

[37] E. Escamilla-Roa, F. Moreno. Planetary and Space Science. 2012.

[38] D. Ross, D. Deamer. Astrobiology 2019.

[39] J. Wu, Z. S. Zhang, X. W. Yu, H. H. Pan, W. G. Jiang, X. R. Xu, R. K. Tang. Chinese Sci. Bull. 2011.

[40] A. Brack. Chemistry and Biodiversity. 2007. 


\section{GRAPHICAL ABSTRACT}

\section{Sofiene Achour, Zied Hosni, and Sarra Darghouthi,Christopher Syme}

\section{Solvent effect on dipeptide bond formation: glycine as a case study}

Peptide bond formation is an important factor to understand the origin of life. Dipeptides are molecules made of two amino acids like the glycine. The effect of glycine solvation such as in water, methanol, and cyclohexane is investigated. Methanol is slightly better than water to leverage peptide bond formation. Energetic results in the gas environment are very close to those obtained in water, suggesting that peptide bonds can be formed under interstellar conditions.

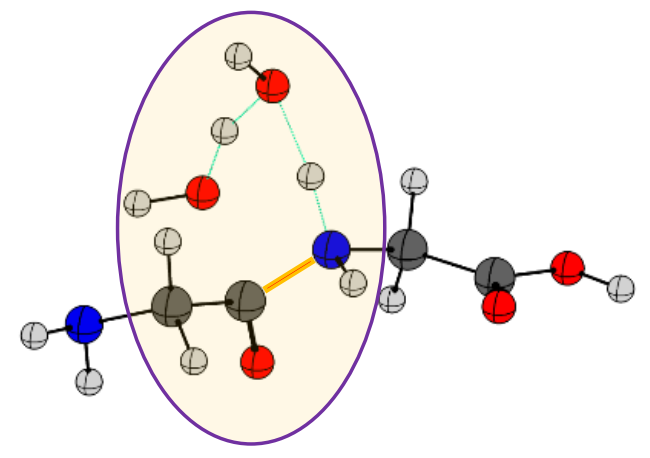


Solvents effect on dipeptide bond formation glycine as a ... (825.67 KiB) view on ChemRxiv • download file 


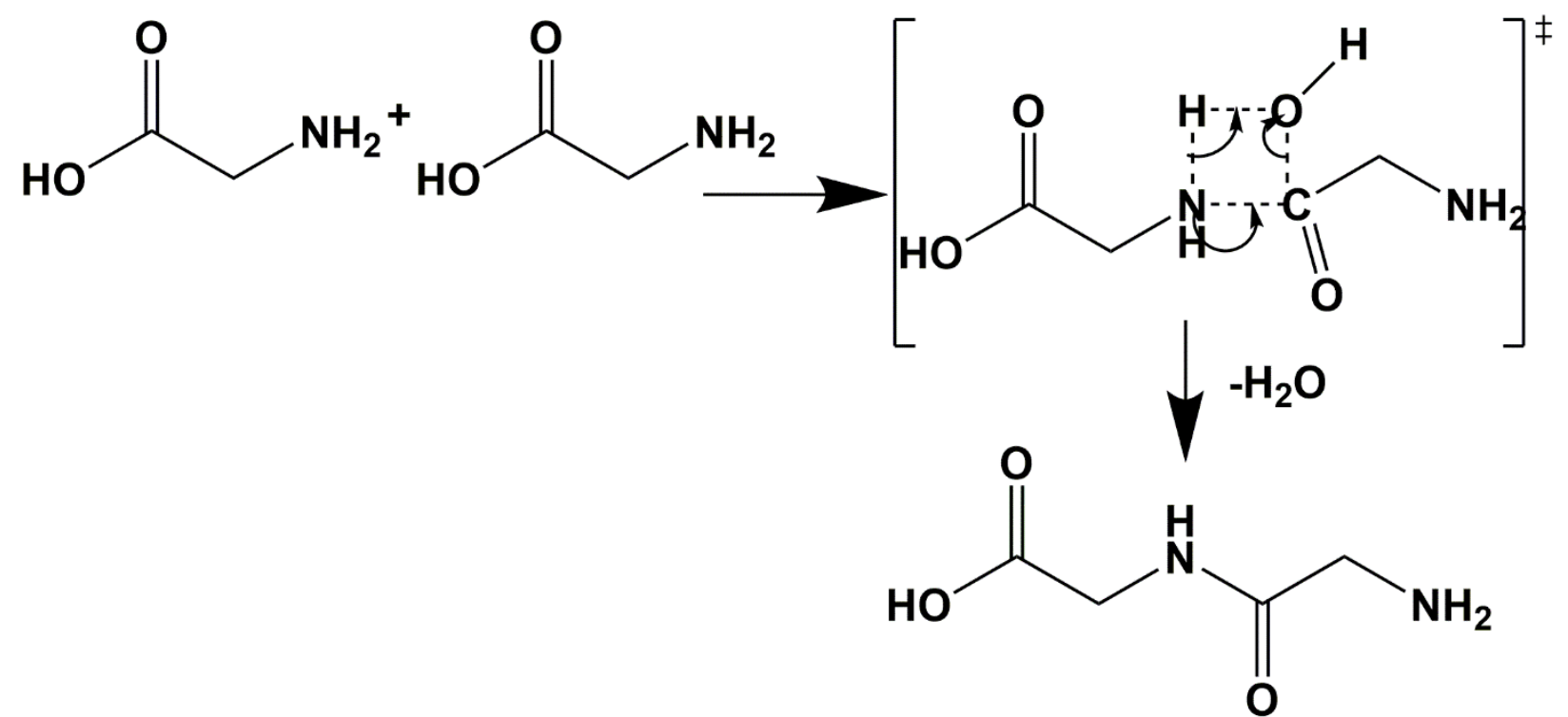

Figure 1. Schematic of the reaction mechanism for peptide bond formation between two amino acids in the gas phase. 


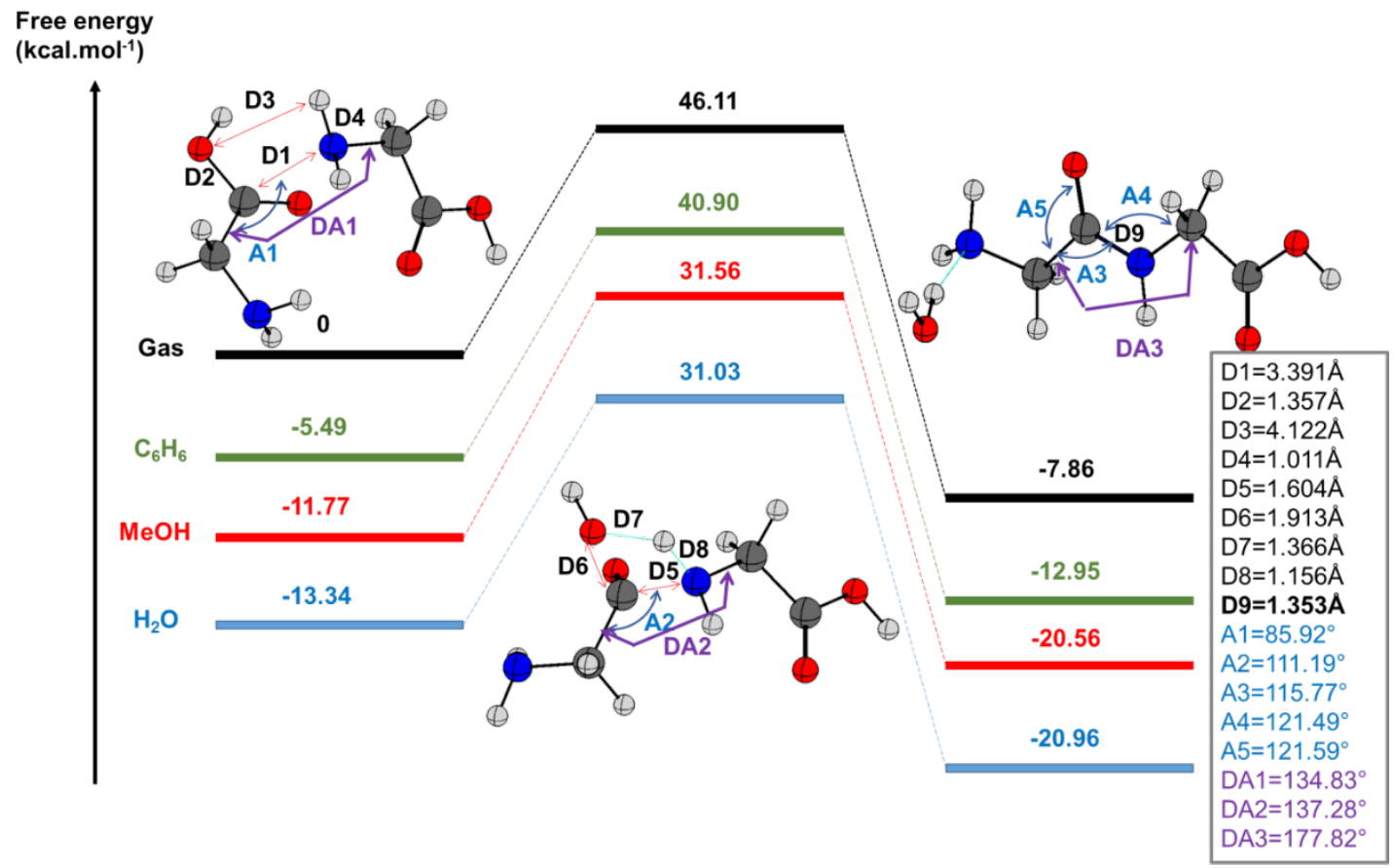

Figure 2. The relative energies of the reactants, products and their transition state (TS) structure for the peptide bond formation between two glycine molecules are given in $\mathrm{kcal}^{\mathrm{mol}}{ }^{-1}$ and calculated at the B3LYP/6-311++(2d,2p) level of theory for four different solvation media. The most relevant distances, angles and dihedral angles in the gas state were listed on the right side.

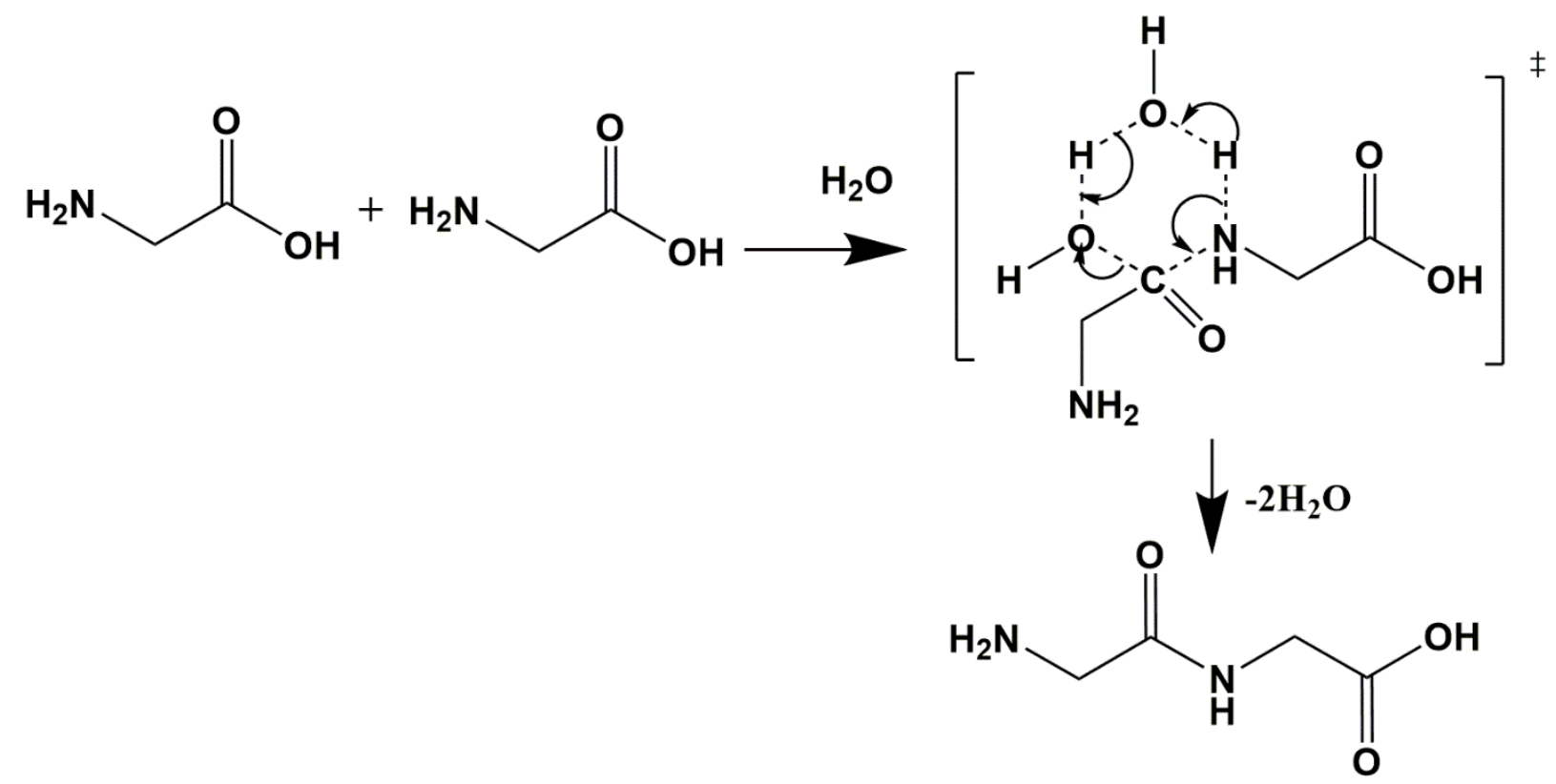

Figure 3. Schematic of the reaction mechanism for explicitly assisted peptide bond formation by water molecules between two amino acids. 


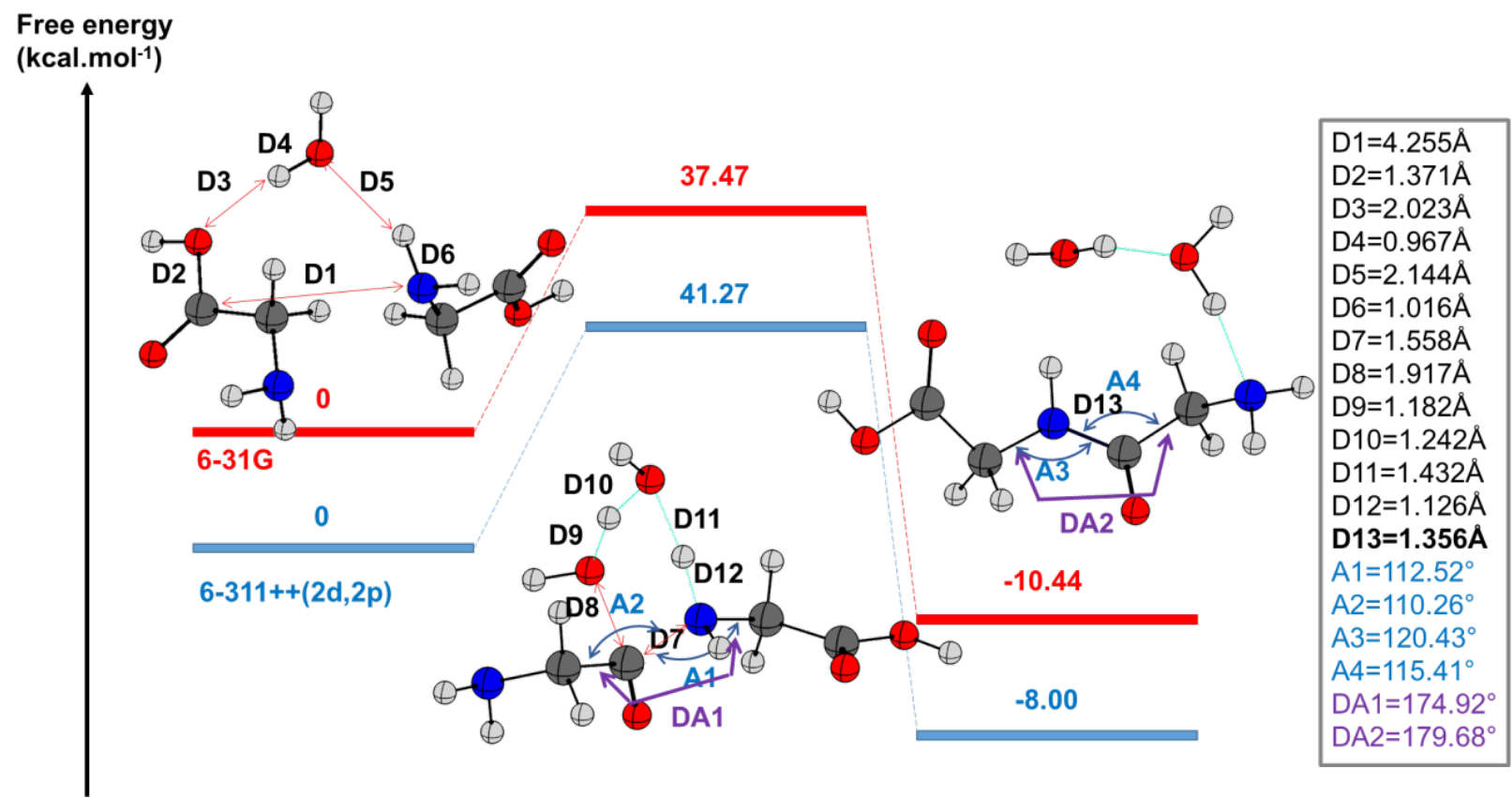

Figure 4. The relative energies of the reactants, products and their transition state (TS) structure for the peptide bond formation between two glycine molecules are given in $\mathrm{kcal}^{\mathrm{mol}}{ }^{-1}$ and calculated at the B3LYP/6-31 $(p, d)$, and B3LYP/6-311++(2d,2p) level of theory. The most relevant distances, angles and dihedral angles in the gas state were listed on the right side.

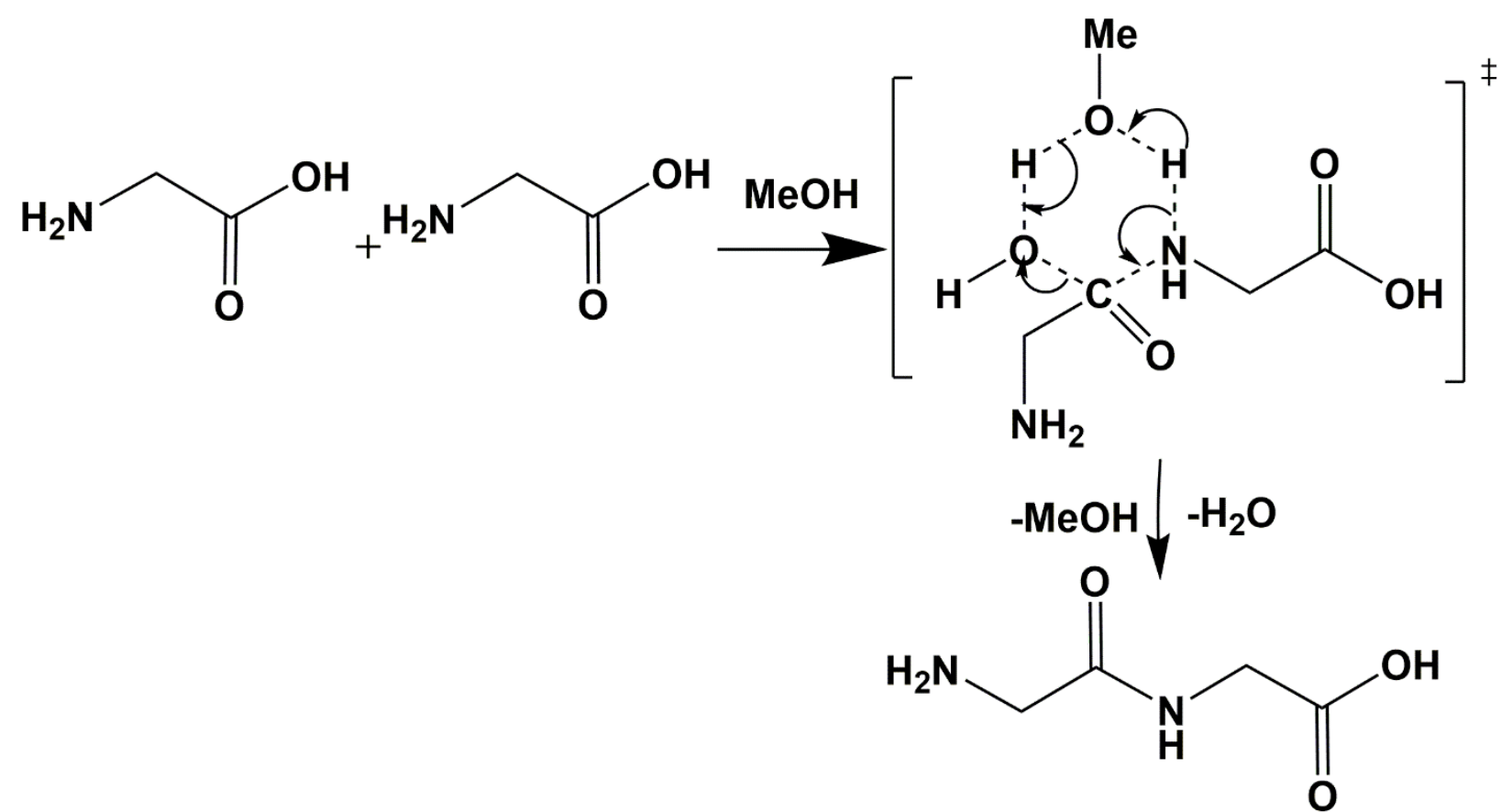

Figure 5. Schematic of the reaction mechanism for explicitly assisted peptide bond formation by methanol molecule between two amino acids. 


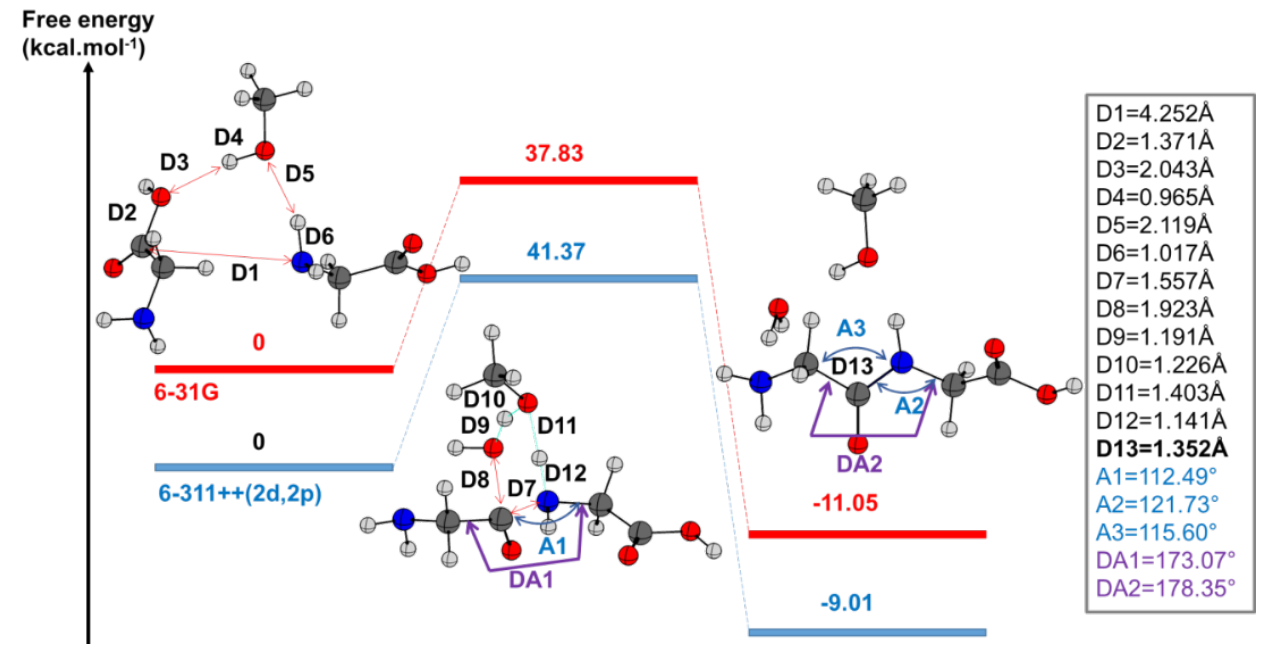

Figure 6. The relative energies of the reactants, products and their transition state (TS) structure for the peptide bond formation between two glycine molecules are given in $\mathrm{kcal}^{\mathrm{mol}}{ }^{-1}$ and calculated at the B3LYP/6-31 $(p, d)$, and B3LYP/6-311++(2d,2p) level of theory. The most relevant distances, angles and dihedral angles in the gas state were listed on the right side.

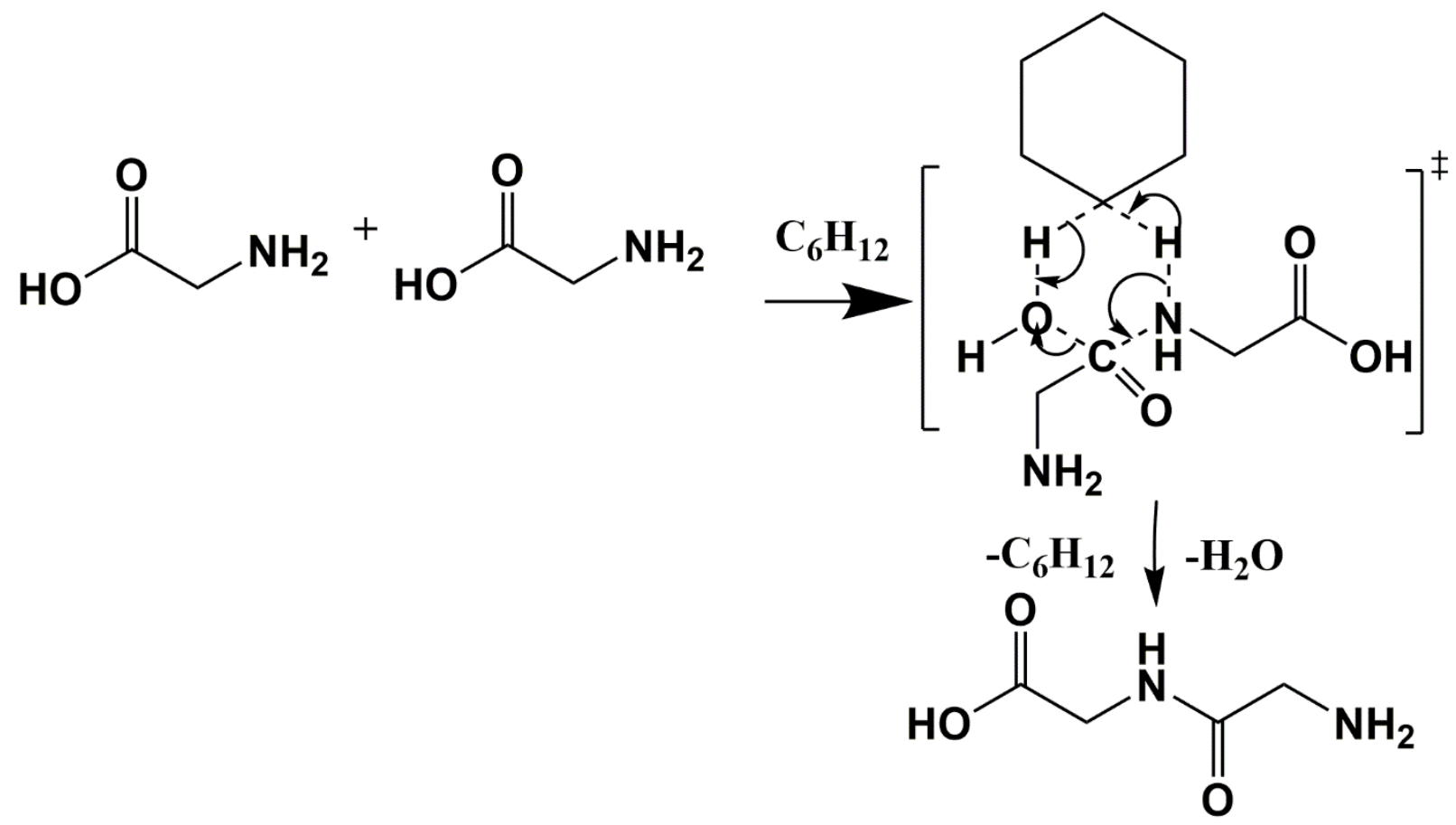

Figure 7. Schematic of the reaction mechanism for explicitly assisted peptide bond formation by cyclohexane molecule between two amino acids. 


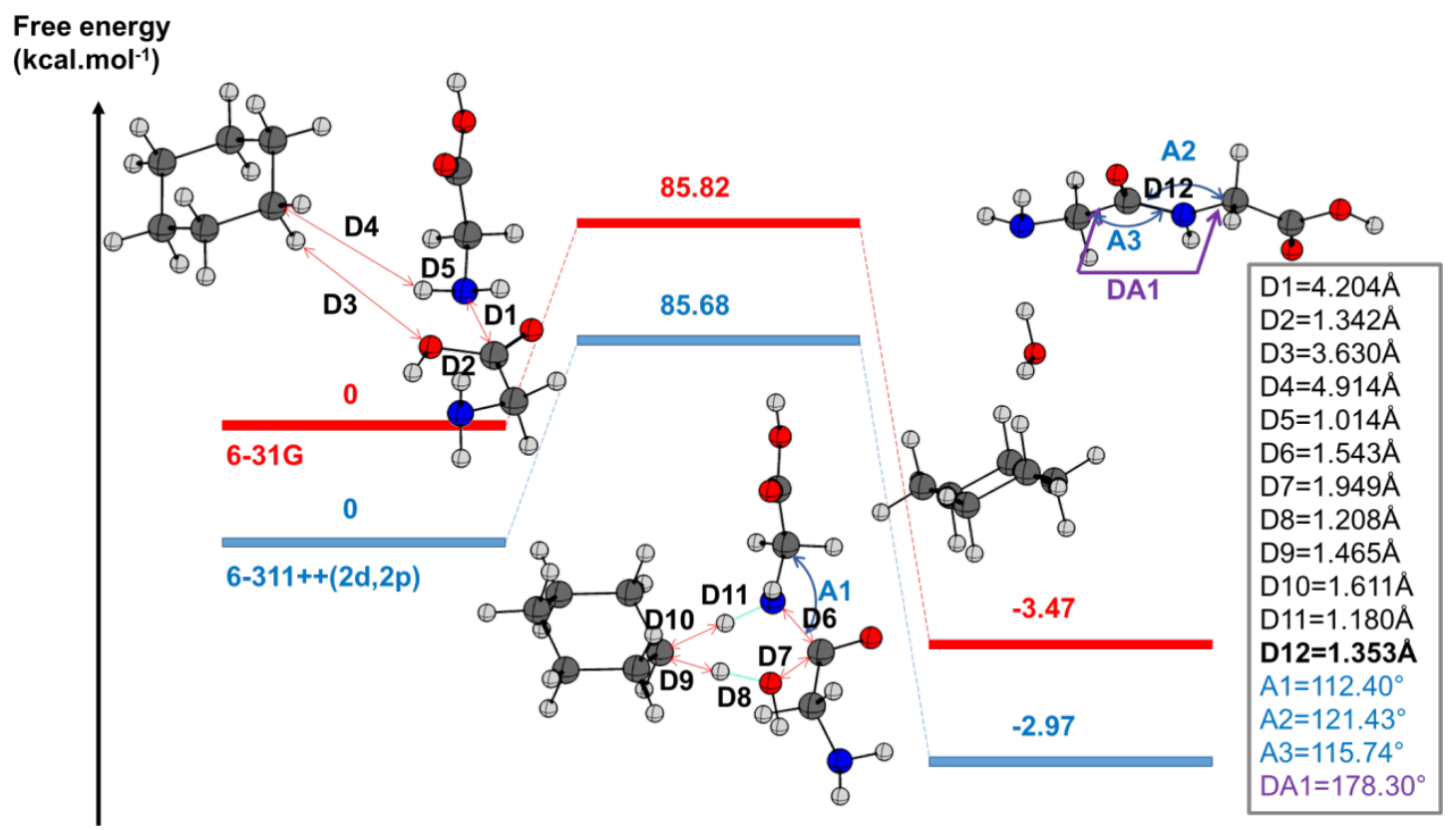

Figure 8. The relative energies of the reactants, products and their transition state (TS) structure for peptide bond formation between two glycine molecules are given in $\mathrm{kcal}^{\mathrm{mol}}{ }^{-1}$ and calculated at the B3LYP/6-31 $(p, d)$, and B3LYP/6-311++(2d,2p) level of theory. The most relevant distances, angles and dihedral angles in the gas state were listed on the right side.
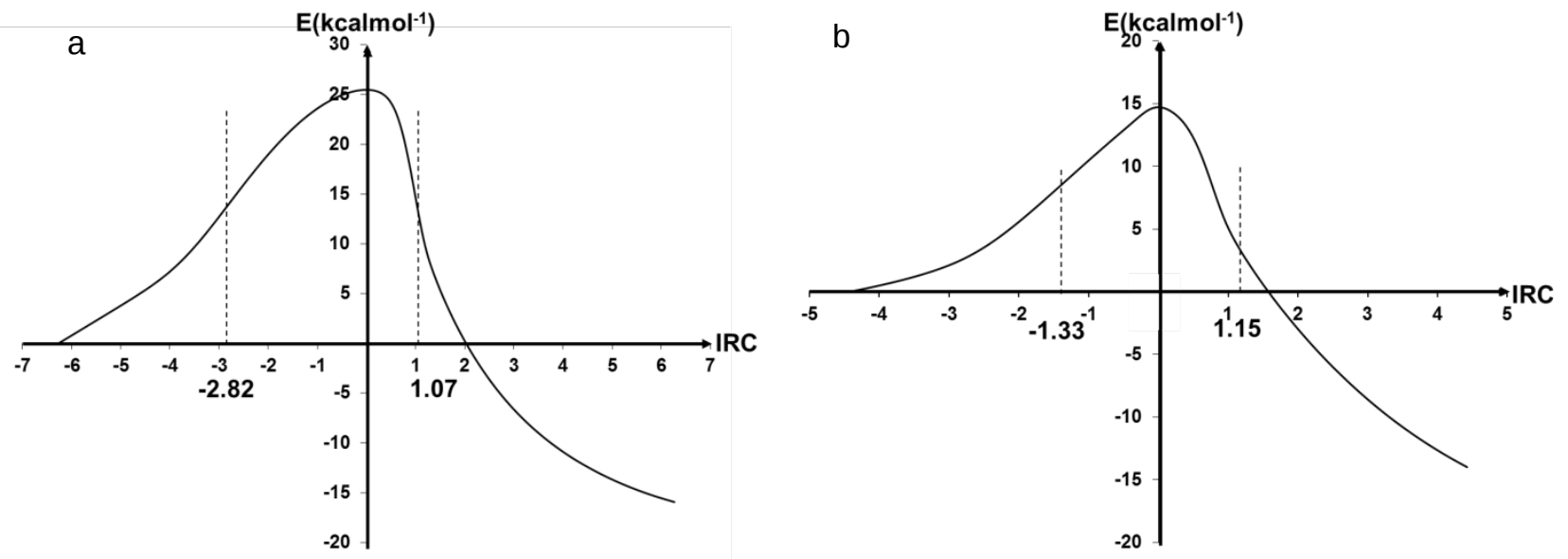

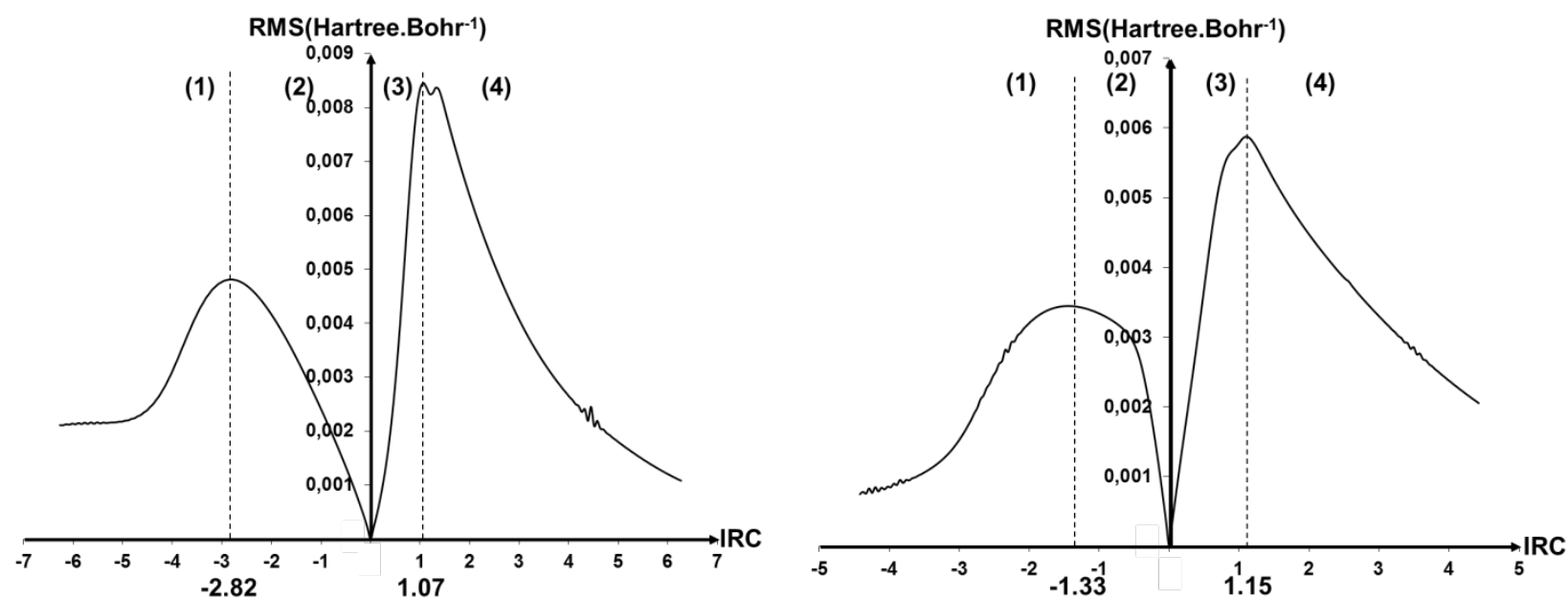

Figure 9. Energetic profiles and their corresponding first derivatives for the dipeptide bond formation: (a) implicitly assisted by water, (b) explicitly assisted by water. 

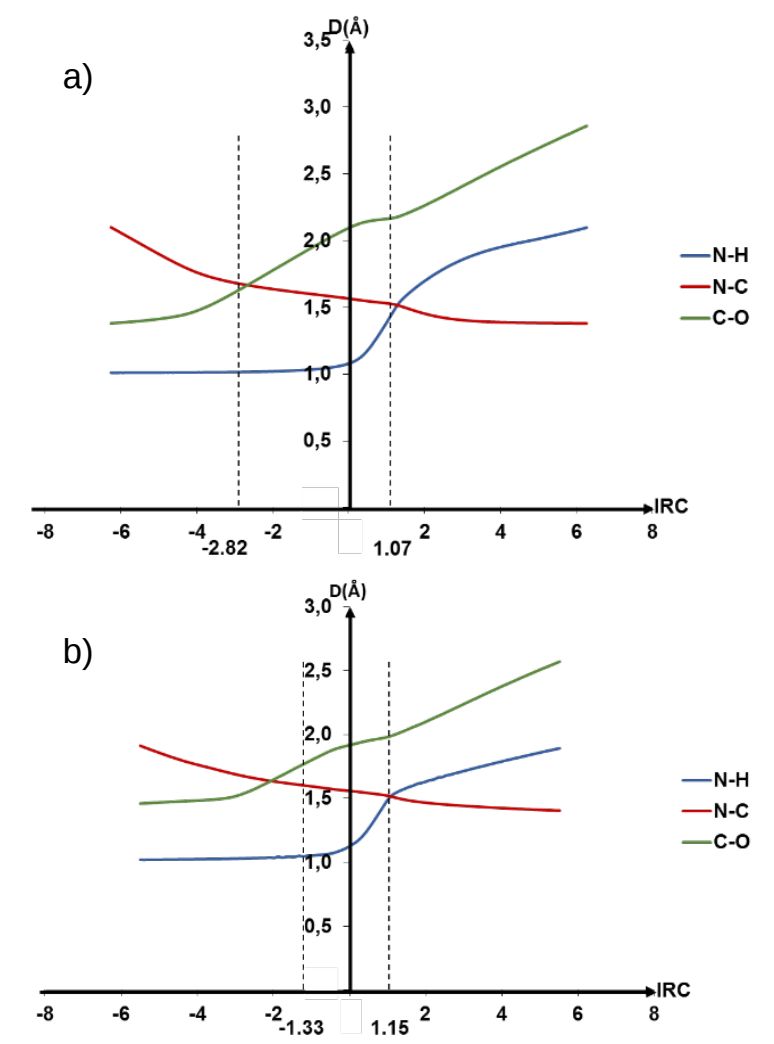

Figure 10. Evaluation of the interatomic distances during the peptide bond formation: a) implicitly assisted by a water molecule, b) explicitly assisted by water molecule. 


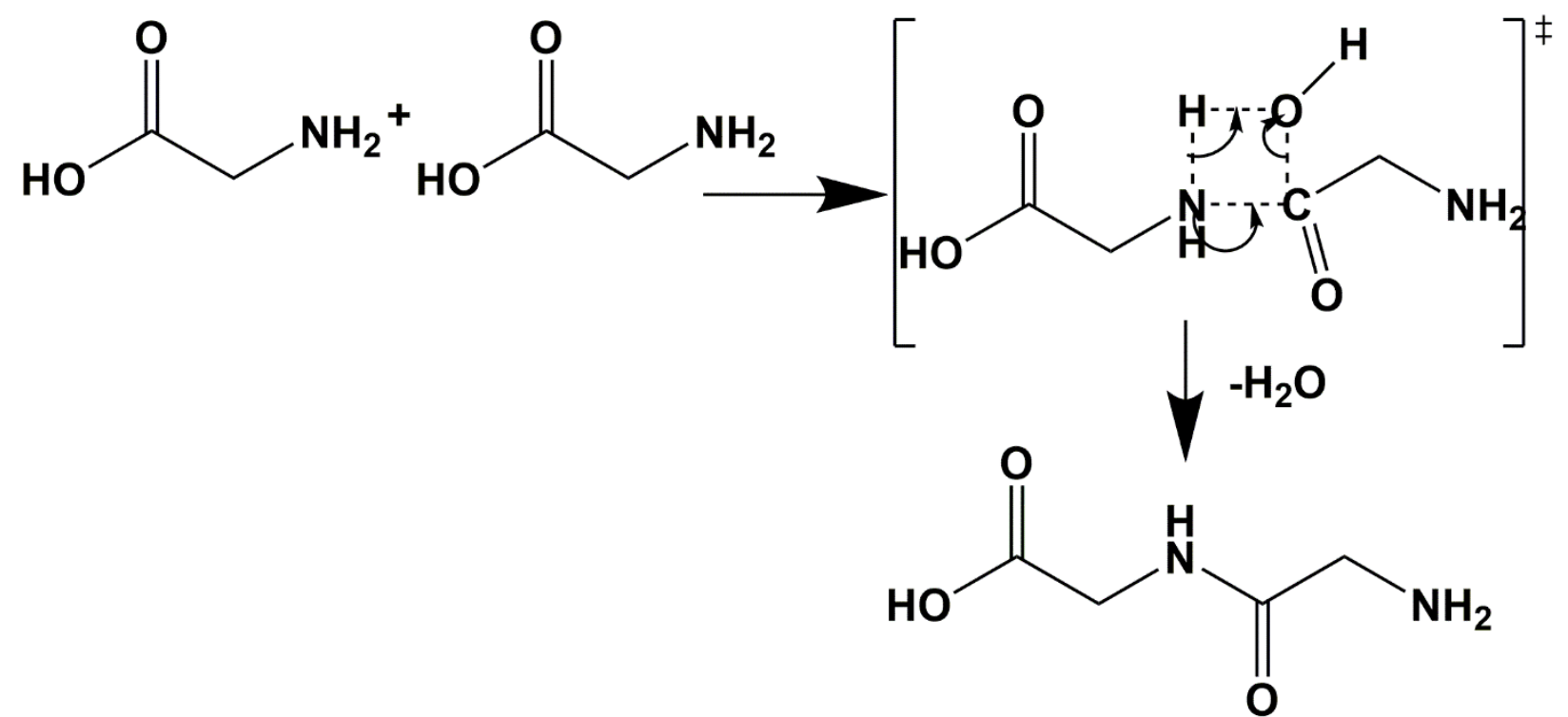

Figure 1. Schematic of the reaction mechanism for peptide bond formation between two amino acids in the gas phase. 


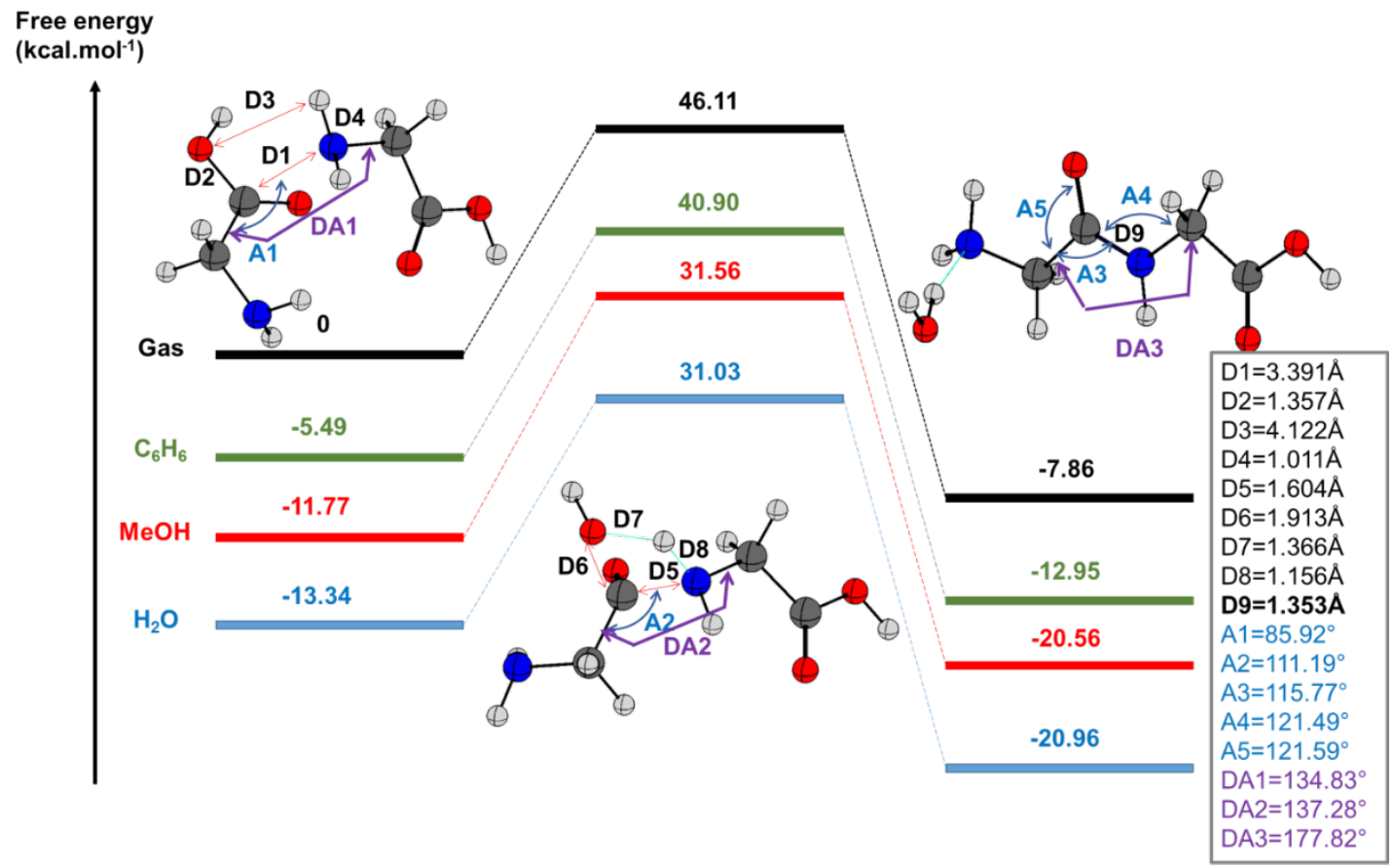

Figure 2. The relative energies of the reactants, products and their transition state (TS) structure for the peptide bond formation between two glycine molecules are given in $\mathrm{kcal}^{\mathrm{mol}}{ }^{-1}$ and calculated at the B3LYP/6-311++(2d,2p) level of theory for four different solvation media. The most relevant distances, angles and dihedral angles in the gas state were listed on the right side.

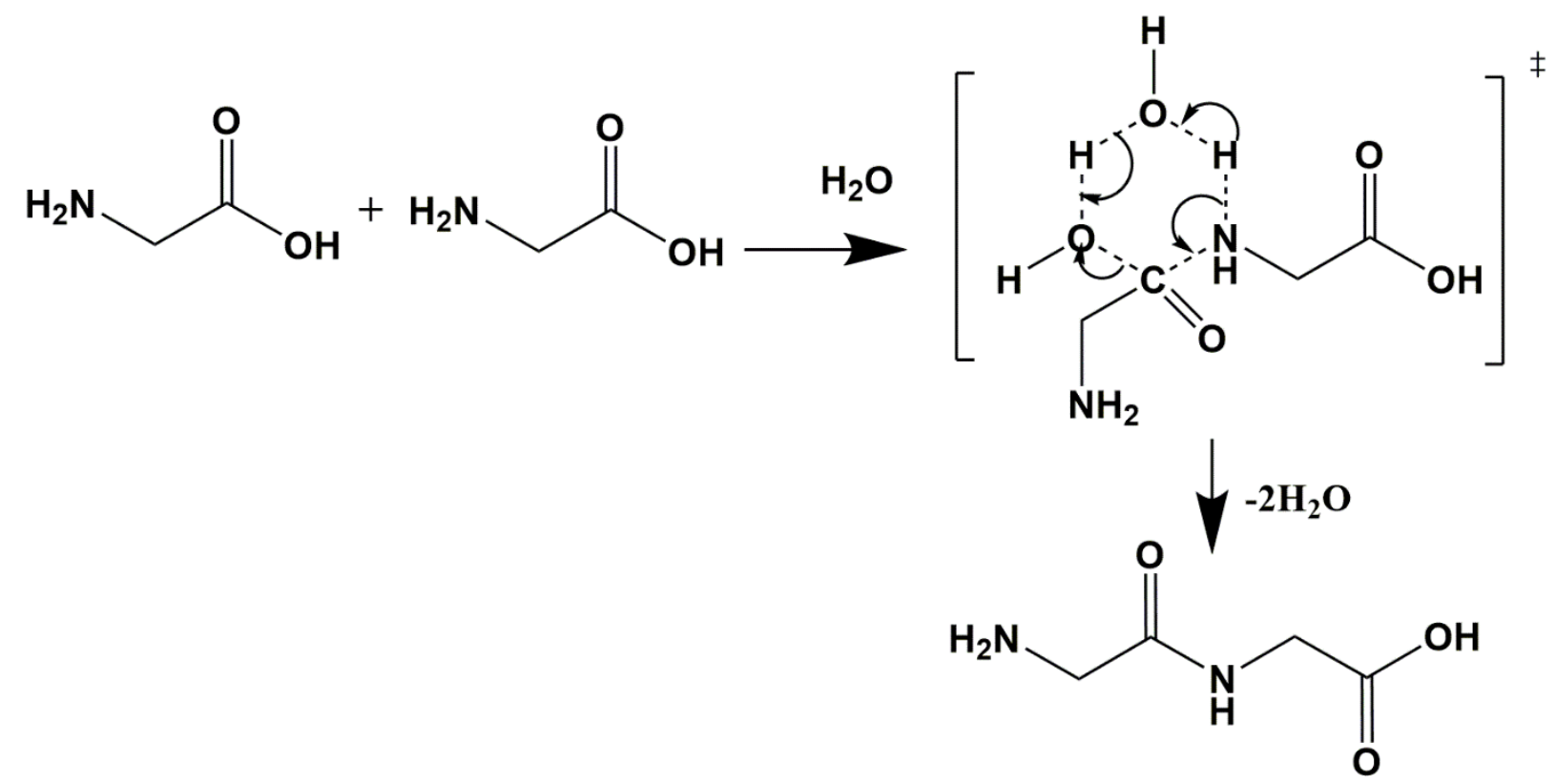

Figure 3. Schematic of the reaction mechanism for explicitly assisted peptide bond formation by water molecules between two amino acids. 


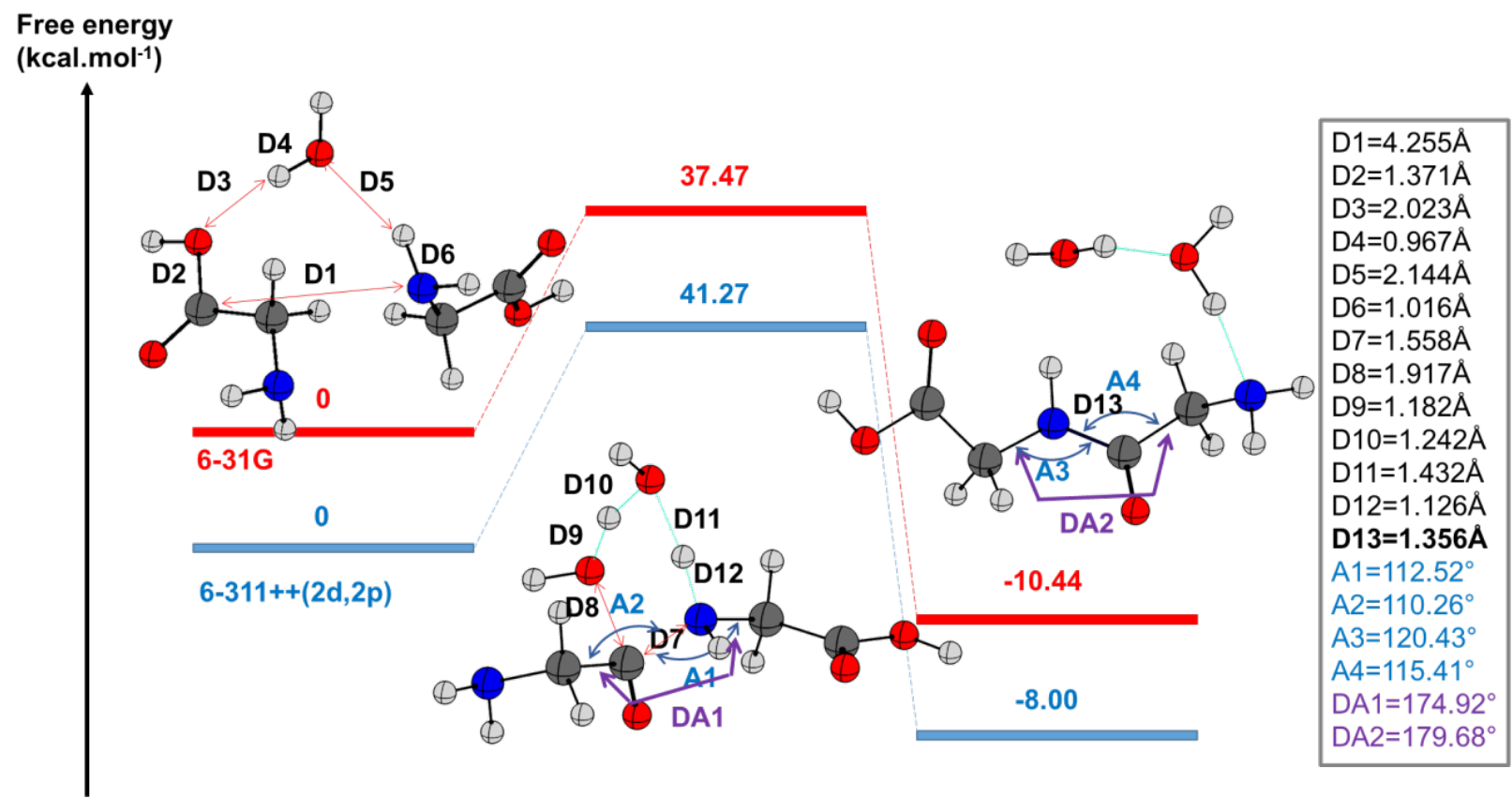

Figure 4. The relative energies of the reactants, products and their transition state (TS) structure for the peptide bond formation between two glycine molecules are given in $\mathrm{kcal}^{\mathrm{mol}}{ }^{-1}$ and calculated at the B3LYP/6-31 $(p, d)$, and B3LYP/6-311++(2d,2p) level of theory. The most relevant distances, angles and dihedral angles in the gas state were listed on the right side.

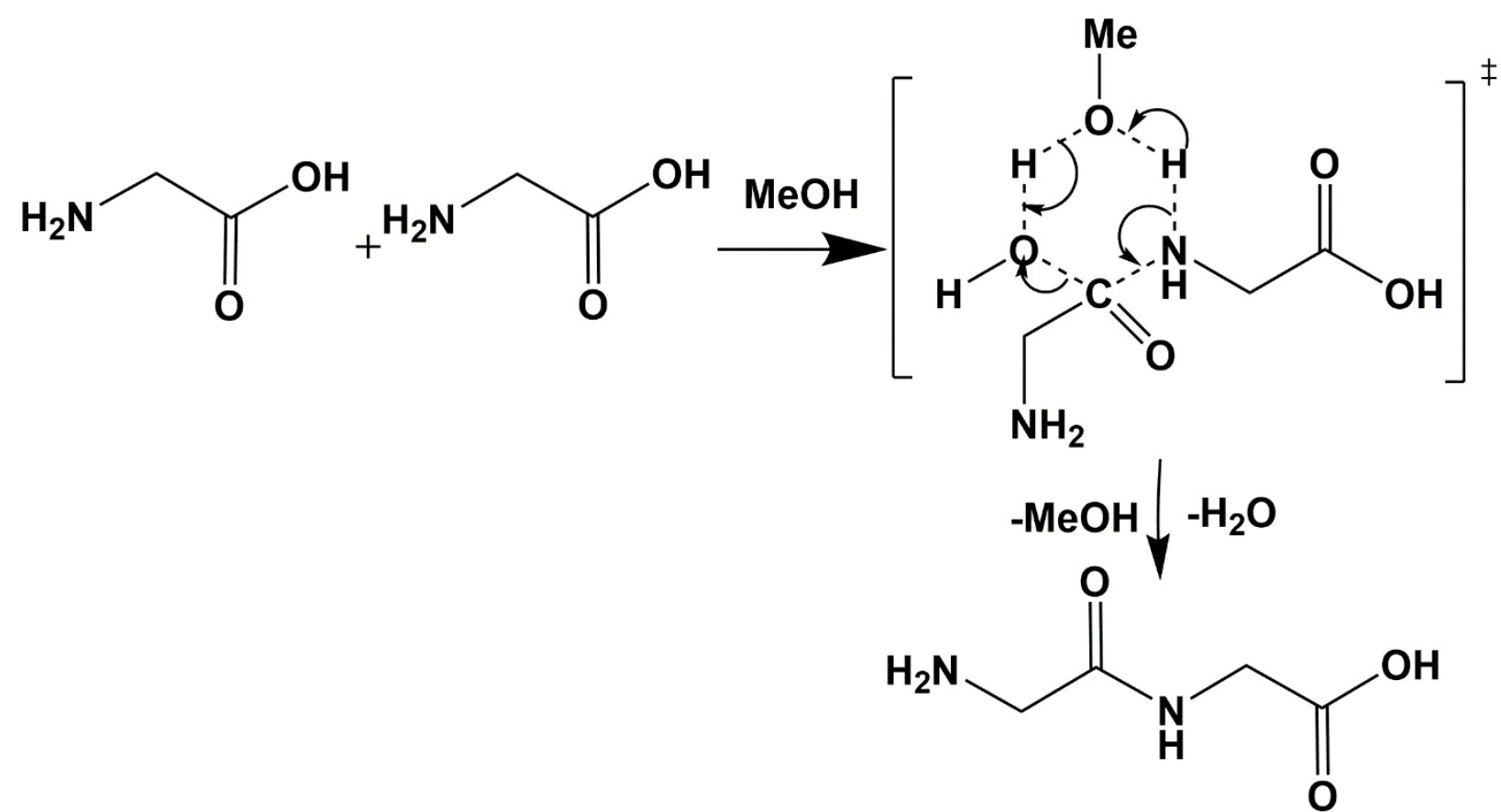

Figure 5. Schematic of the reaction mechanism for explicitly assisted peptide bond formation by methanol molecule between two amino acids. 


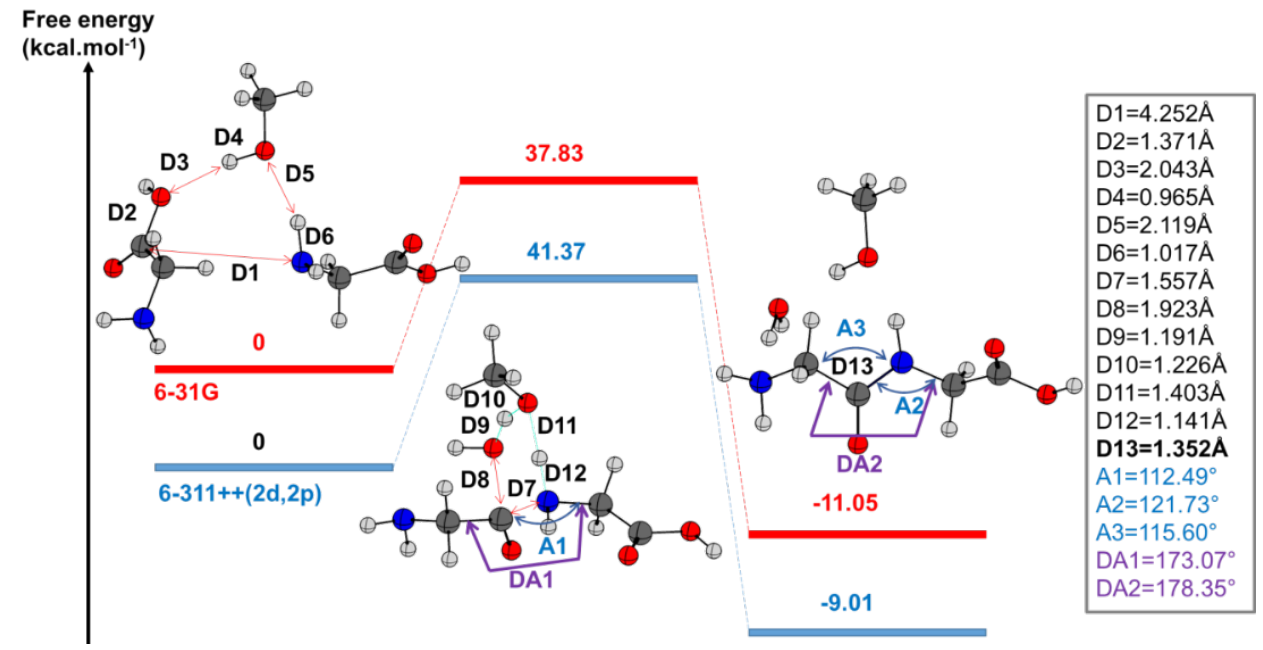

Figure 6. The relative energies of the reactants, products and their transition state (TS) structure for the peptide bond formation between two glycine molecules are given in $\mathrm{kcal}^{\mathrm{mol}}{ }^{-1}$ and calculated at the B3LYP/6-31 $(p, d)$, and B3LYP/6-311++(2d,2p) level of theory. The most relevant distances, angles and dihedral angles in the gas state were listed on the right side.

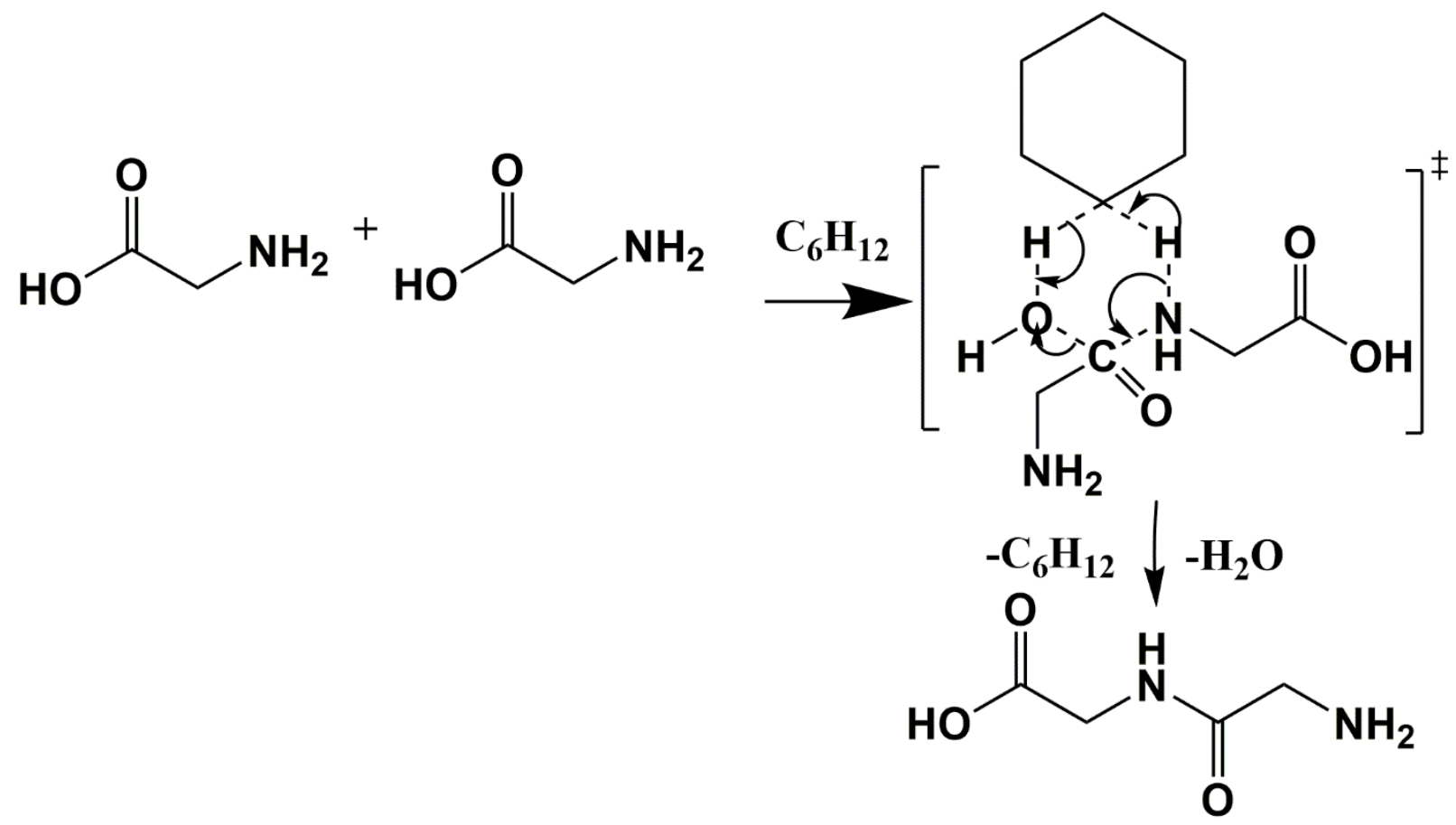

Figure 7. Schematic of the reaction mechanism for explicitly assisted peptide bond formation by cyclohexane molecule between two amino acids. 


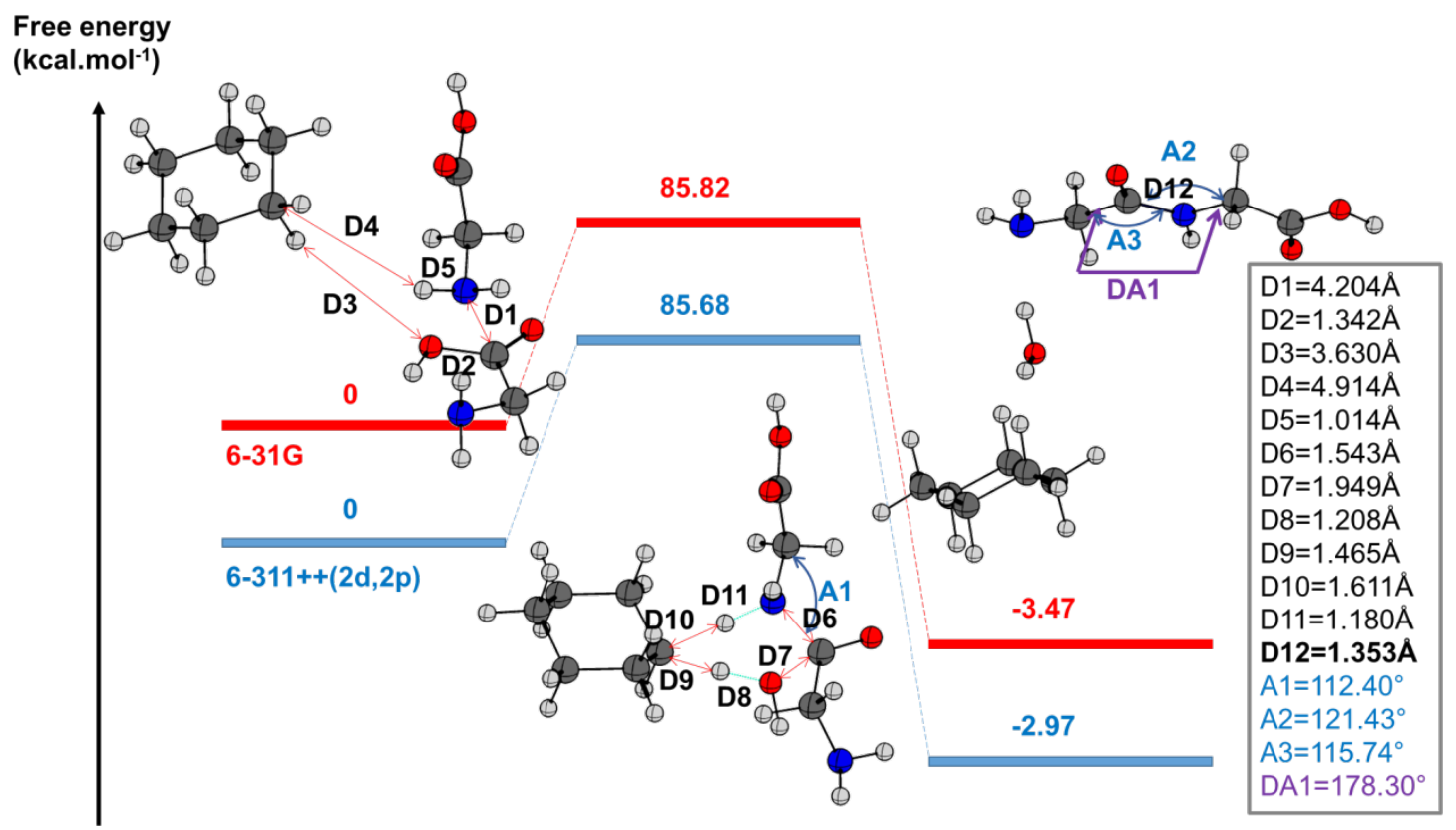

Figure 8. The relative energies of the reactants, products and their transition state (TS) structure for peptide bond formation between two glycine molecules are given in $\mathrm{kcal}^{\mathrm{mol}}{ }^{-1}$ and calculated at the B3LYP/6-31 $(p, d)$, and B3LYP/6-311++(2d,2p) level of theory. The most relevant distances, angles and dihedral angles in the gas state were listed on the right side.
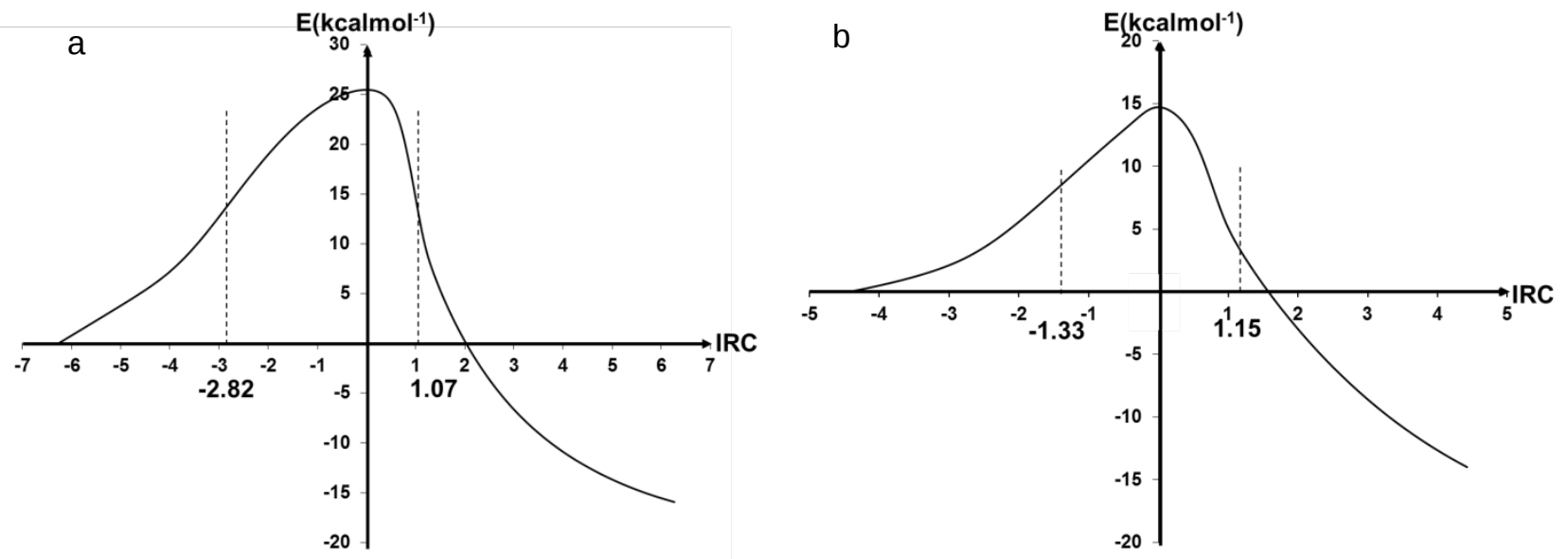

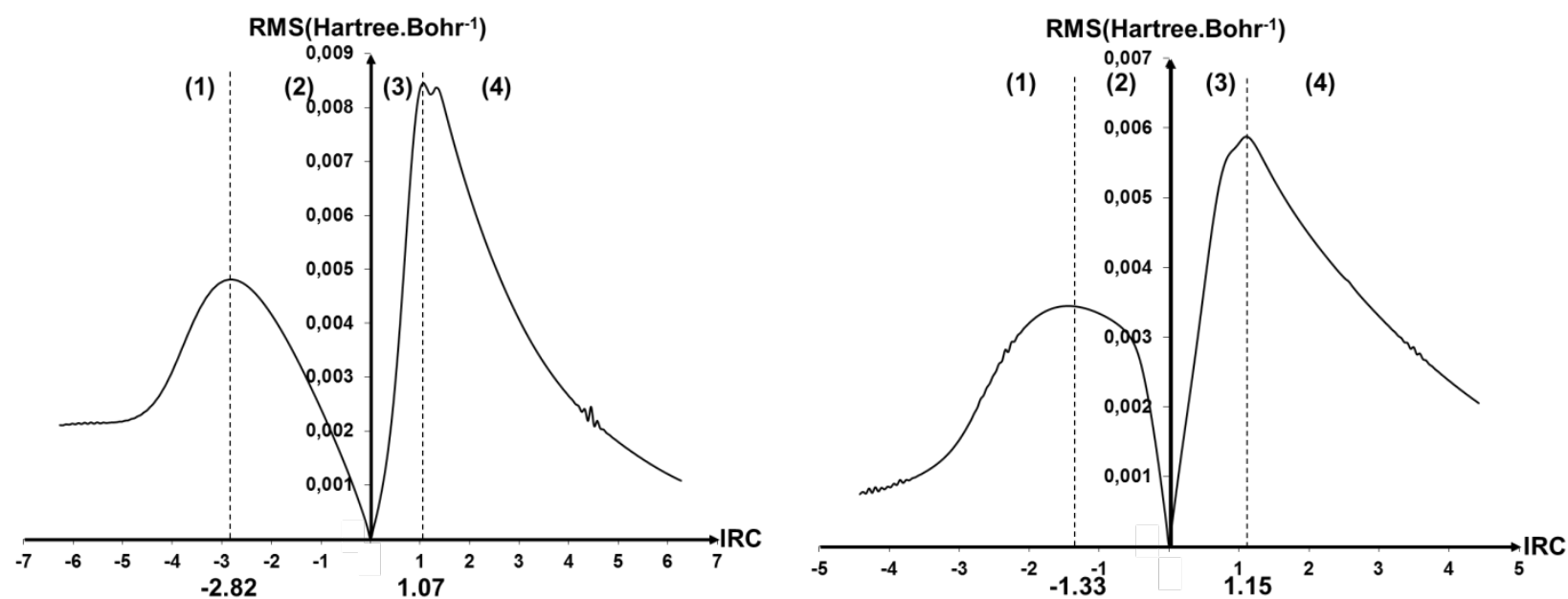

Figure 9. Energetic profiles and their corresponding first derivatives for the dipeptide bond formation: (a) implicitly assisted by water, (b) explicitly assisted by water. 

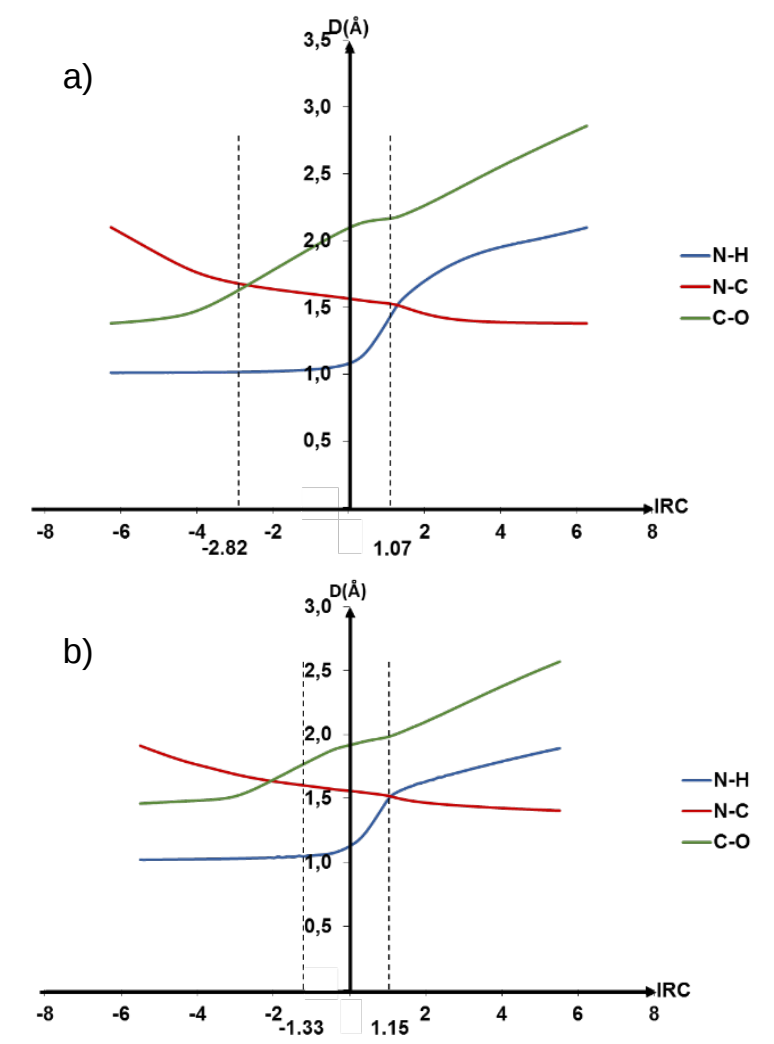

Figure 10. Evaluation of the interatomic distances during the peptide bond formation: a) implicitly assisted by a water molecule, b) explicitly assisted by water molecule. 
